\title{
Diagnóstico y tratamiento de infecciones oportunistas en el paciente adulto con infección por VIH/SIDA
}

\author{
Martín Lasso B., en representación del Comité Consultivo de SIDA. Sociedad Chilena de Infectología
}

\author{
Hospital Dr. Sótero Del Río. \\ Unidad de Infectología \\ Declaración de conflictos de \\ interés: el autor ha participado \\ en protocolos de investigación \\ con las siguientes compañías \\ farmaceúticas: Merck Sharp \\ \& Dohme, GlaxoSmithKline, \\ Abbott, Bayer, Pharmacia \\ Upjohn, Bristol Myers-Squibbs \\ y Shering-Plough. Ha recibido \\ honorarios por participación en \\ reuniones científicas por Bristo \\ Myers-Squibbs y Abbott y apoyo \\ financiero para la asistencia a \\ eventos científicos en el país y en \\ el extranjero por Merck Sharp \& \\ Dohme, Abbott, Bristol Myers- \\ Squibbs, GlaxoSmithKline y Pfizer. \\ Fuentes de financiamiento: $\mathrm{E}$ \\ presente trabajo no tiene fuentes de \\ financiamiento externas.
}

Recibido: 1 de noviembre de 2010

Correspondencia a: Martín Lasso Barreto zoalde@yahoo.com

\section{Diagnosis and treatment of opportunistic infections in HIV/AIDS adult patients}

The following guidelines for the diagnosis and treatment of opportunistic infections (OI) in adult HIV/AIDS patients represent the first approach to standardize the management of this patient group in Chile. The guidelines are based on scientific evidence. They intend to serve as a practical and easy-to-use tool for physicians during the process of selecting appropriate diagnostic tests and effective treatments for their patients. They also include the local experience in Chile related to OI in HIV/AIDS patients. Regular up-dates to include new scientific knowledge are proposed.

Key words: Opportunistic infections, HIV/AIDS, guidelines.

Palabras clave: Infecciones oportunistas, VIH, SIDA, Guías.

\section{Introducción}

L as presentes guías están elaboradas principalmente en base a las guías norteamericanas de tratamiento de infecciones oportunistas $(\mathrm{IO})^{1}$ y adaptadas a la realidad y experiencia local. Se excluyen los fármacos que no se encuentran disponibles en Chile, ni se establecen en la primera línea de tratamiento aquellos que por su elevado costo no suelen usarse en la práctica clínica habitual.

Estas guías están concebidas para una evolución dinámica en el tiempo debiendo renovarse con regularidad acorde con la velocidad de las innovaciones en la medicina y que, a su vez, sean una ventana abierta para las contribuciones de los diversos centros de atención de personas afectados por infección por VIH del país. En esta misma dirección, se irán incorporando las nuevas publicaciones internacionales y nacionales relacionadas que vayan sucediéndose.

No se incluyen en estas guías el manejo de la infección por hepatitis viral dado que existe un documento en elaboración al respecto. Tampoco, salvo la enfermedad de Chagas, no se menciona el manejo de IO tropicales por lo inhabitual de estas enfermedades en Chile; no obstante, en un futuro se las podrá incluir.

A estas guías se les ha dado un enfoque eminentemente práctico y conciso, con el fin de que sea un apoyo rápido y eficiente para todos los colegas pero especialmente para los médicos no especialistas, que representan un grupo importante de los facultativos que atienden pacientes infectados con VIH. Se incluye el nivel de evidencia de la terapia utilizada en cada caso (Tablas 1 y 2). La finalidad última de estas guías es tener criterios homogéneos al momento del diagnóstico y brindar el mejor y más oportuno tratamiento cuando una IO se presente en nuestros pacientes.

\section{Infecciones oportunistas fúngicas}

\section{Neumonía por Pneumocystis jiroveci}

\section{Diagnóstico}

Esta IO se caracteriza por falla respiratoria subaguda, fiebre, tos no productiva y molestias torácicas inespecíficas, de días a semanas de evolución. Puede presentarse únicamente con fiebre. El examen físico pulmonar suele ser anodino y en ocasiones no hay ningún signo. En los casos graves existe hipoxemia $\left(\mathrm{PO}_{2}<70 \mathrm{mmHg}\right)$ que se traduce inicialmente por un descenso en la saturación de oxígeno ante el ejercicio leve, lo que nos demuestra un gradiente alveolo-arterial de $\mathrm{O}_{2}$ anormal. El neumotórax es una complicación asociada frecuente de los cuadros graves.

La enzima lactato deshidrogenasa (LDH) en sangre puede estar elevada más de tres veces sobre el valor normal, lo cual es altamente sensible pero poco específico ${ }^{2}$. La proteína $\mathrm{C}$ reactiva (PCR) suele ser baja cuando no existe co-infección por otros agentes infecciosos ${ }^{3}$. La radiografía de tórax muestra infiltrados intersticiales bilaterales "en alas de mariposa", pero puede tener patrones variables con presencia de nódulos, bulas o cualquier tipo de patrón radiológico. La TAC de pulmón demuestra, clásicamente, imágenes en vidrio esmerilado o de "árbol en brote".

Entre 13 y $18 \%$ de los pacientes con neumonía por $P$. jiroveci tienen una co-infección: neumonía bacteriana, tuberculosis (TBC) o sarcoma de Kaposi ${ }^{4}$.

El método clásico de diagnóstico es por medio de la expectoración inducida o el lavado bronco-alveolar. Las tinciones utilizadas pueden ser Giemsa o Wright (útil para quistes y trofozoitos pero no tiñen la pared), 
Gomori Grocott metenamina de plata o Gram (tiñen la pared del quiste). La búsqueda de $P$. jiroveci con estas tinciones es operador dependiente y es necesario tener experiencia para descartar la presencia del agente. La inmunofluorescencia directa es una técnica más sensible y no depende del operador. Las técnicas de biología molecular, como la reacción de polimerasa en cadena (RPC), resultan promisorias para la identificación de $P$. jiroveci; sin embargo, hay que recordar que un porcentaje no despreciable de la población está colonizada con este microorganismo ${ }^{5,6}$.

\section{Tratamiento}

No se debe aplazar el tratamiento de la neumonía por $P$. jiroveci a la espera de detectar el agente etiológico; en algunos casos se puede rescatar el agente aún después de semanas de tratamiento La terapia anti-retroviral (TARV) debe iniciarse precozmente en los pacientes con neumonía por $P$. jiroveci leve a moderada y luego de las primeras dos semanas de tratamiento en los casos más graves y que requieren de ventilación mecánica ${ }^{7}$. El fármaco de elección para el tratamiento de la neumonía por $P$. jiroveci es la combinación de trimetoprim y sulfametoxazol (cotrimoxazol) ${ }^{8,9}$ (AI) que ha sido ampliamente probado y tiene presentación iv para aquellos casos más graves que requieren manejo en una unidad de pacientes críticos (Tabla 3). Los caminos a seguir en caso de alergia al cotrimoxazol es desensibilizar ${ }^{10}$ (Tabla 4 ) o recurrir a una alternativa consistente en primaquina y clindamicina ${ }^{9,11,12}$ BI. En los casos graves con falla respiratoria $\left(\mathrm{PaO}_{2}<70\right.$ $\mathrm{mmHg}$ ) es perentorio el uso de corticosteroides que pueden representar en ciertas instancias la acción terapéutica más importante para recuperar al paciente ${ }^{13}$.

\section{Criptococcosis}

\section{Diagnóstico}

Se manifiesta principalmente como meningitis o meningo-encefalitis y se caracteriza por fiebre, cefalea y

\begin{tabular}{|cl|}
\hline & \multicolumn{1}{c}{ Tabla 1.} \\
\hline Grado de evidencia & Tipo de diseño de investigación \\
\hline I & Evidencia obtenida de al menos un estudio randomizado, controlado \\
\hline II & $\begin{array}{l}\text { Evidencia obtenida de al menos un estudio controlado, no randomizado, } \\
\text { de cohorte o caso control }\end{array}$ \\
\hline III & $\begin{array}{l}\text { Evidencia obtenida de expertos, opinión y/o experiencia clínica de auto- } \\
\text { ridades reconocidas }\end{array}$ \\
\hline
\end{tabular}

\section{Tabla 2.}

Grado de recomendación Fortaleza de las recomendaciones

Evidencia fuerte a favor

Evidencia moderada a favor

Opcional

No debe ofrecerse en forma rutinaria

No debe usarse bajo ninguna condición

compromiso del estado general. Los signos clásicos de rigidez de nuca y fotofobia son menos habituales (25-30\%) que en la meningitis bacteriana aguda. El compromiso de funciones mentales superiores y del nivel de conciencia es poco frecuente y se ven más bien en etapas tardías de la enfermedad.

El LCR puede ser normal o mostrar alteraciones discretas: proteínas elevadas, glucosa baja o normal e incremento de la celularidad a expensas de linfocitos. Se ha descrito recientemente la asociación de LCR poco inflamatorio (leucocitos $<25$ céls $/ \mathrm{mL}$ y proteínas $<50$ $\mathrm{mg} / \mathrm{dL}$ ) con mayor riesgo de desarrollo de un síndrome de reconstitución inmune $(\mathrm{SRI})^{14}$. La presión de apertura es elevada en $75 \%$ de los pacientes y rebasa los $20 \mathrm{~cm}$ de $\mathrm{H}_{2} \mathrm{O}$; esto se manifiesta durante el procedimiento de punción lumbar (PL) por un goteo acelerado de LCR.

\begin{tabular}{|c|c|c|}
\hline Condición clínica & Terapia de elección (21 días) & Alternativa (21 días) \\
\hline $\begin{array}{l}\text { Neumonía grave } \\
\mathrm{PaO}_{2}<70 \mathrm{mmHg} \text { con } \mathrm{FiO}_{2} 21 \% \mathrm{o} \\
\text { Diferencia alvéolo-arterial de } \mathrm{O}_{2}>35 \mathrm{mmHg}\end{array}$ & $\begin{array}{l}\text { Trimetoprim (80 mg) Sulfametoxazol ( } 400 \text { mg) (Cotrimoxazol)* } \\
\text { Dosis } \\
15-20 \mathrm{mg} \text { de T y } 75-100 \mathrm{mg} \text { de } \mathrm{S} \text { kg/día/ iv cada } 6 \mathrm{~h} \\
\text { Puede pasar a vo ante mejoría clínica } \\
\text { Corticosteroides** }\end{array}$ & $\begin{array}{l}\text { Primaquina } 15 \text { - } 30 \mathrm{mg} \text { (base) vo }+ \\
\text { Clindamicina } 600 \text { a } 900 \mathrm{mg} \text { iv c/6 a } 8 \mathrm{~h} . \\
\text { Puede pasar a vo con clindamicina: } 300 \text { a } 450 \mathrm{mg} \mathrm{c/6} \text { a } 8 \mathrm{~h} \\
\text { Corticosteroides** }\end{array}$ \\
\hline Neumonía no grave & Las mismas dosis vo & Las mismas dosis vo \\
\hline Profilaxis secundaria & Cotrimoxazol: (80/400 o 160/800 mg) vo/día (Al) & Desensibilizar en lo posible (ver Tabla 4) \\
\hline \multicolumn{3}{|c|}{ 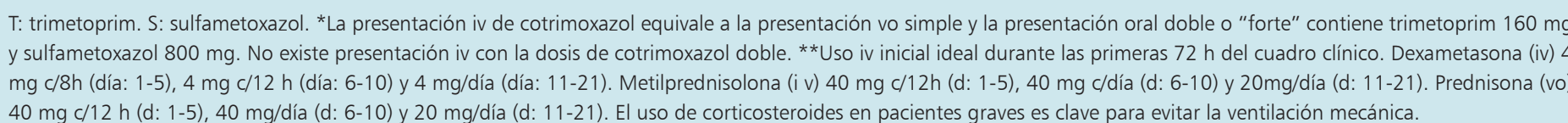 } \\
\hline
\end{tabular}


Tabla 4. Esquema de desensibilización oral rápida, se realiza con jarabe presentación pediátrica*. Después de cada dosis se debe tomar 50 cc de agua

\begin{tabular}{|c|c|c|}
\hline Hora & Dosis T/S mg & Volumen a administrar en $\mathrm{mL}$ \\
\hline 0 & $0,004 / 0,02$ & $\begin{array}{l}\text { Obtener } 0,5 \mathrm{~mL} \text { de jarabe }+9,5 \mathrm{~mL} \mathrm{H}_{2} \mathrm{O} \text { (Sol 1) } \\
\text { Obtener } 1 \mathrm{~mL} \text { de Sol } 1+9 \mathrm{~mL} \mathrm{H} \mathrm{H}_{2}(\mathrm{Sol} 2) \\
\text { Obtener } 1 \mathrm{~mL} \text { de Sol } 2+9 \mathrm{~mL} \mathrm{H} \mathrm{H}_{2}(\mathrm{Sol} 3) \\
\text { Obtener } 1 \mathrm{~mL} \text { de Sol } 3+9 \mathrm{~mL} \mathrm{H} \mathrm{H}_{2} \text { (Sol 4) } \\
\text { Tomar: } 10 \mathrm{~mL} \text { de Sol } 4\end{array}$ \\
\hline 1 & $0,04 / 0,2$ & Tomar: $10 \mathrm{~mL}$ de Sol 3 \\
\hline 2 & $0,4 / 2$ & Tomar: $10 \mathrm{~mL}$ de Sol 2 \\
\hline 3 & $4 / 20$ & Tomar: $10 \mathrm{~mL}$ de Sol 1 \\
\hline 4 & $40 / 200$ & Tomar: $5 \mathrm{~mL}$ de jarabe \\
\hline 5 & $160 / 800$ & Tomar: $20 \mathrm{~mL}$ de jarabe \\
\hline
\end{tabular}

Tabla 5. Tratamiento de la meningitis causada por Cryptococcus spp

Anfotericina B 0,7 mg/kg/día iv + fluconazol $400 \mathrm{mg} /$ día iv por 14 días

Terapia de consolidación

Fluconazol $400 \mathrm{mg} /$ día vo o

Itraconazol $200 \mathrm{mg} \mathrm{c} / 12 \mathrm{~h}$ vo por 10 semanas

Terapia de mantención

Fluconazol 200 mg/día o itraconazol 200 mg/día vo permanente hasta conseguir valores de linfocitos T-CD4 > 200 céls con TARV lando la negativización de Cryptococcus spp en el LCR. Anfotericina B en formulación lipídica y 5-flucitosina, asociada a anfotericina, son opciones pero no se las ha incluido dado el alto costo de la primera y la inexistencia de la segunda en Chile.

En caso de presión elevada de salida de LCR o compromiso del sensorio se debe realizar PL diaria con extracción de 20 a $30 \mathrm{ml}$ de LCR hasta que la presión de salida se normalice o se puede dejar un drenaje transitorio de LCR para los casos más graves o en quienes no se pueda realizar PL consecutivas ${ }^{17}$. Es recomendable realizar siempre un control de LCR una vez completadas dos semanas de tratamiento para confirmar la erradicación del agente.

Un $30 \%$ de los pacientes puede desarrollar un SRI grave al iniciar concomitantemente TARV; por ello se recomienda su inicio una vez concluida la fase de inducción de dos semanas, en especial en los casos más graves. Cuando se presenta un SRI se puede apoyar con corticosteroides. Se podría tomar antigenemia para Cryptococcus spp en pacientes con L-CD4 < de 100 céls/ $\mathrm{mm}^{3}$ a modo de una búsqueda dirigida de la enfermedad subclínica, con el objeto de tratar preventivamente con fluconazol los casos positivos que inician TARV. Esta práctica ha demostrado tener un costo-beneficio claro y podría disminuir la mortalidad relacionada a la infección por Cryptococcus spp ${ }^{18}$.

\section{Candidiasis}

\section{Diagnóstico}

Las candidiasis orofaríngea y esofágica son posiblemente las infecciones oportunistas más frecuentes y evidentes en los pacientes con infección por VIH con inmunosupresión grave (linfocitos T-CD4 $<200$ céls/mL). A su vez, son un marcador clínico muy útil respecto de la respuesta a la TARV temprana pues frecuentemente no recurren luego de su tratamiento específico en pacientes adherentes y con buena respuesta a TARV. En mujeres también se presenta en forma recurrente candidiasis vulvovaginal.

El principal agente es Candida albicans pero hay que tener presentes otras especies como C. glabrata o $C$. krusei en los casos refractarios a fluconazol ${ }^{19}$.

Se caracteriza por disfagia, odinofagia y pérdida de peso. Es frecuente encontrar esta IO en el contexto de un paciente emaciado, con dermatitis seborreica. No se asocia a fiebre y no suele presentar un compromiso sistémico aunque, excepcionalmente, se encuentra asociado a candidemia en pacientes que contraen infecciones con cepas resistentes a fluconazol ${ }^{20}$.

El diagnóstico se establece mediante la visión directa de lesiones blanquecinas solevantadas múltiples en la orofaringe; también pueden presentarse como lesiones 
eritematosas no ulceradas o queilitis angular. La candidiasis esofágica se manifiesta con disfagia, odinofagia, ardor y dolor retroesternal y se confirma mediante la visión de lesiones en la endoscopia digestiva alta. Debido a la urgencia de tener un tubo digestivo eficiente para la nutrición y la TARV la práctica habitual es tratar inmediatamente los casos sospechosos de compromiso esofágico (algorra bucal y trastornos deglutorios) y dejar la endoscopia para aquellos casos con fracaso clínico. Se puede hacer tinción de $\mathrm{KOH}$ (visión de levaduras) y el cultivo respectivo en Cromoagar para poder diferenciar entre C. albicans y Candida spp no albicans ${ }^{1}$.

\section{Tratamiento}

El fármaco de elección es fluconazol ${ }^{21}(\mathrm{AI})$. Experiencia local ha demostrado que con siete días de tratamiento las lesiones desaparecen en su totalidad ${ }^{22}$; no obstante, las guías norteamericanas recomiendan 14 días ${ }^{1,21}$ (Tabla 6) y dosis más altas, especialmente en candidiasis esofágica. Fármacos como anfotericina $\mathrm{B}$, voriconazol o caspofungina $^{1}$ (CII) debe dejarse para los casos refractarios a fluconazol y con cultivos que demuestren la presencia de Candida no albicans ${ }^{19}$. La candidiasis vulvovaginal se puede tratar con azólicos tópicos o monodosis de fluconazol oral.

\section{Aspergilosis}

\section{Diagnóstico}

La aspergilosis invasora no representa un problema menos habitual que en otros grupos de pacientes inmunodeprimidos como: neutropénicos, pacientes sometidos a trasplantes de órganos o en quimioterapia. Por el contrario, es sub-diagnosticada y se ha demostrado la presencia de aspergilosis invasora en estudios de autopsia de pacientes con infección por VIH/SIDA en 15 a $25 \%$ de las veces y cerca de la mitad de los casos no son diagnosticados en vida ${ }^{23}$. El contexto en el que ocurre es el de recuento de linfocitos T-CD4 $<100$ céls $/ \mathrm{mL}$, con otras IO y sin TARV. La localización más habitual es pulmonar y se presenta clínicamente como una neumonía necrosante o una traqueo-bronquitis ${ }^{24}$. Hay fiebre, disnea, dolor torácico, tos, hemoptisis e hipoxemia. Las imágenes radiográficas son variables y en la tomografía pulmonar de corte fino pueden encontrarse el signo del halo o de la luna creciente. Puede presentarse también, con mayor frecuencia, como un aspergiloma pulmonar asociado o no a $\mathrm{TBC}^{25}$ y haber compromiso en otros tejidos: SNC, cavidades paranasales, hueso y piel. El diagnóstico se establece por el cuadro clínico más la visión directa de hifas septadas dicotómicas y con brazos en ángulo de $45^{\circ} \mathrm{y}$ cultivos repetidos positivos para Aspergillus spp en tejido. El diagnóstico se confirma por histología demostrando la invasión de hifas al parénquima pulmonar. El test de ELISA “en sandwich" para galactomano, principal componente de la pared fúngica, es ampliamente usado como parte del diagnóstico de aspergilosis en pacientes neutropénicos post-quimioterapia y en trasplantados ${ }^{26}$. Durante el proceso diagnóstico se puede establecer tres categorías de aspergilosis invasora pulmonar, de acuerdo al nivel de certeza que se podrían aplicar al paciente $\mathrm{VIH}^{27,28}$ (Tabla 7).

\section{Tratamiento}

El fármaco de elección para esta entidad es voriconazol (BIII) ${ }^{1,27}$ (Tabla 8). No se ha definido en el paciente con infección por VIH por cuánto tiempo debe prolongarse esta terapia; la conducta más adecuada es que una vez resuelta la infección clínicamente y por

\begin{tabular}{|c|c|c|}
\hline Situación clínica & Terapia de elección & Duración \\
\hline Candidiasis orofaríngea & $\begin{array}{l}\text { Fluconazol } 100 \text { mg/día } \\
\text { Miconazol 1/4 de cuchara de medida c/6 h d* }\end{array}$ & 7 días \\
\hline Candidiasis esofágica & Fluconazol 150-200 mg/día/vo & 7-14 días \\
\hline $\begin{array}{l}\text { Candidiasis refractaria a fluconazol } \\
\text { (asociado a Candida no albicans } \\
\text { en cultivos) }\end{array}$ & $\begin{array}{l}\text { Anfotericina B 0,3 mg/kg/ iv/día } \\
\text { Voriconazol } 200 \mathrm{mg} \text { iv o vo c/12 h } \\
\text { Caspofungina } 50 \mathrm{mg} \text { iv/día }\end{array}$ & 14 días \\
\hline \multicolumn{3}{|c|}{$\begin{array}{l}\text { *Un tubo (Daktarin }{ }^{\circledR} \text { ) contiene } 40 \mathrm{~g} \text { de gel, cada cucharadita de medida: } 5 \mathrm{~mL} \text {, lo que corresponde a } \\
124 \text { mg de miconazol. Hay que mantener el gel en la boca el mayor tiempo posible y luego deglutir. } \\
\text { No se incluyen los colutorios de nistatina dado su mal sabor y la presencia de opciones más efectivas. }\end{array}$} \\
\hline
\end{tabular}

\section{Tabla 7. Diagnóstico de aspergilosis invasora pulmonar, de acuerdo al grado de certeza}

\begin{tabular}{|c|c|c|c|}
\hline Aspergilosis & Clínico/radiológico: & Galactomanano & Cultivo sitio estéril y/o histológico \\
\hline Posible & $\begin{array}{l}\text { Fiebre, tos, dolor pleural y hemoptisis } \\
\text { Nódulo, halo, signo de aire crescente, cavidades e infiltrados nuevos inespecíficos } \\
\text { en pulmón }\end{array}$ & Negativo & Negativo \\
\hline Probable & Igual que aspergilosis posible & Positivo & Negativo* \\
\hline Probada & Igual que aspergilosis posible & Positivo o negativo & Positivo \\
\hline
\end{tabular}




\begin{tabular}{|lll|}
\hline \multicolumn{2}{c|}{ Tabla 8. Tratamiento de la aspergilosis } \\
\hline Situación clínica & Terapia de elección & Alternativas \\
\hline Aspergilosis invasora & $\begin{array}{l}\text { Voriconazol } 6 \mathrm{mg} / \mathrm{kg} / \mathrm{c} 12 \mathrm{~h} \text { por } 1 \mathrm{día} \text { y } \\
\text { luego } 4 \mathrm{mg} / \mathrm{kg} / \mathrm{c} / 12 \mathrm{~h} \text { iv } \\
\end{array}$ & $\begin{array}{l}\text { Anfotericina B } 1 \mathrm{mg} / \mathrm{kg} \text { iv } \\
\text { Una vez estabilizado pasar a } 200 \mathrm{mg} \mathrm{c} / 12 \mathrm{~h} \text { vo }\end{array}$ \\
\hline
\end{tabular}

imágenes, se espere llegar a un recuento de linfocitos T-CD4 > 200 céls/mL para suspender el tratamiento. Debe tenerse precaución con la asociación voriconazol y TARV, especialmente con los inhibidores de proteasa (IP). Ritonavir está contraindicado ya que reduce de modo crítico los niveles plasmáticos de voriconazol; por otro lado, se ha establecido que la asociación de efavirenz y voriconazol incrementa la toxicidad del primero y reduce las concentraciones plasmáticas del segundo, por lo que también está contraindicado ${ }^{29}$. También son efectivos para tratar una aspergilosis: itraconazol, cuya presentación para uso parenteral no está disponible en Chile, posaconazol, las equinocandinas y anfotericina en formulación lipídica.

\section{Infecciones causadas por micobacterias}

\section{Tuberculosis}

\section{Diagnóstico}

La TBC en el paciente con infección por VIH representa una infección primaria en $1 / 3$ de los casos, y una reactivación de infección latente en $2 / 3$ de ellos ${ }^{1}$. A su vez, causa la muerte en $13 \%$ de los pacientes infectados por VIH, según la $\mathrm{OMS}^{30}$.

En los individuos con inmunidad relativamente preservada (linfocitos T-CD4 > 350 céls $/ \mathrm{mL}$ ), las manifestaciones clínicas de TBC son similares a las de los pacientes seronegativos para VIH: compromiso pulmonar predominante, fiebre y sudoración prolongada, tos $\mathrm{y}$, ocasional expectoración hemoptoica por más de dos semanas, radiografía de tórax con infiltrados nodulares apicales, con o sin cavernas. En los pacientes con mayor inmunosupresión, los patrones radiográficos pueden ser de cualquier tipo, incluyendo compromiso intersticial, miliar e incluso imágenes normales, requiriendo diagnóstico diferencial con micobacterias atípicas. La TBC extra-pulmonar como linfadenitis, pleuritis, pericarditis, meningitis y septicemia, es más frecuente en los pacientes con infección por VIH, por lo que se la debe buscar dirigidamente. En pacientes asintomáticos, la TBC puede manifestarse como parte del SRI, incluso con sólo siete días de TARV.

El diagnóstico se establece de acuerdo al estadio de la TBC.
Tuberculosis latente: Se diagnostica mediante el test cutáneo de tuberculina por el método de Mantoux, ampliamente conocido y que consiste en la aplicación de $0,1 \mathrm{~mL}$ intradérmico del derivado proteico purificado (PPD) de $5 \mathrm{U}$, siendo positiva una induración $>5 \mathrm{~mm}$ (especificidad 56-95\%). Una prueba alternativa que se deberá usar con mayor frecuencia en el futuro es la medición de IFN gamma (QuantiFERON ${ }^{\circledR}$ y TBSpot ${ }^{\circledR}$ ) específico para péptidos de Mycobacterium tuberculosis (especificidad 92-97\%), que tiene menor reactividad cruzada con la cepa del BCG (bacilo de Calmette-Guérin) $\mathrm{u}$ otras micobacterias no tuberculosas ${ }^{31}$.

Tuberculosis activa: Para su diagnóstico debe obtenerse una muestra del sitio de la infección (v.g. esputo, ganglio, serosa, hueso, LCR) para tinción ácido-alcohol resistente, cultivo en medios automatizados, cuyo resultado está en una a tres semanas y cultivo en medio clásico (Löwenstein-Jenssen) que tarda entre tres y ocho semanas. La muestra de expectoración se debe obtener en tres ocasiones, idealmente en la mañana, a días alternos y procesar bajo el método de concentración, que incrementa significativamente la sensibilidad de la baciloscopia ${ }^{32}$. No se recomienda pruebas para TBC latente por el alto porcentaje $(25 \%)$ de falsos negativos ${ }^{33}$. La determinación de adenosin deaminasa (ADA) en el diagnóstico de TBC extra-pulmonar es ampliamente usada en nuestro medio; valores superiores a 7, 36, 40 y $80 \mathrm{UI} / \mathrm{mL}$ son utilizados para el diagnóstico de TBC meníngea, peritoneal, pericárdica y pleural, respectivamente ${ }^{34,35}$. La RPC se debería aplicar en todo espécimen en que se busque TBC pero, debido a la presencia de falsos negativos, su resultado debe manejarse con cautela. Un resultado positivo nos obliga a iniciar el tratamiento respectivo ${ }^{36}$. Ante un cultivo positivo, siempre es necesario realizar estudio de susceptibilidad in vitro para los fármacos de primera línea ${ }^{36}$. Debe repetirse los cultivos y realizarse estudio de sensibilidad para fármacos anti TBC de segunda línea en las siguientes situaciones: pacientes con terapia antituberculosa previa, contacto de pacientes con enfermedad tuberculosa resistente a la terapia, resistencia demostrada a cualquiera de los fármacos de primera línea, cultivos positivos luego de tres meses de tratamiento o que vuelven a ser positivo luego de un mes o más de haberse negativizado, provenir de regiones con alta prevalencia de TBC multi-resistente (MR) o extensamente resistente (ER). Se 
considera fracaso al tratamiento según la norma ministerial ${ }^{37}$ : la persistencia de baciloscopias positivas a los cuatro meses de tratamiento (18 semanas); sin embargo, este hecho no es infrecuente en paciente con infección por VIH y no VIH con TBC pulmonar y/o ganglionar, y no necesariamente representa un fracaso ${ }^{38}$. Cuando la TBC es diagnosticada o se sospecha con un sustento clínico válido, el tratamiento debe ser iniciado inmediatamente y no esperar el resultado de las pruebas confirmatorias. Este enfoque facilita la muerte rápida del bacilo de Koch, previene la emergencia de cepas resistentes y disminuye el período de contagiosidad.

\section{Tratamiento}

La terapia anti-tuberculosa en el paciente con infección por VIH debe ser más intensiva y prolongada $(\mathrm{AI})^{1,39,40}$. Las principales modificaciones que se introducen hacen referencia al uso constante, sin excepción, de cuatro fármacos en la fase de inducción, el cambio de fase bisemanal a trisemanal, con el ajuste respectivo de dosis, y a los tiempos de tratamiento más prolongados ${ }^{39-44}$. Estas modificaciones representan una propuesta para ser analizada y difieren de las guías nacionales ${ }^{37}$ (Tabla 9). En Chile, el tratamiento de la TBC en pacientes seropositivos para VIH e inmunocompetentes no difiere y consiste en isoniazida (HIN), rifampicina (RFP), pirazinamida (PZ) y etambutol (ETB) por 50 dosis (2 meses) seguido de HIN y RFP por 32 dosis (4 meses) en la TBC bacilífera. En la TBC extra-pulmonar con bacteriología negativa es similar, con la sola excepción de ETB que no se usa. Debe recordarse siempre adicionar piridoxina a la HIN y corticosteroides para TBC pericárdica y meníngea ${ }^{45}$
(Tabla 9). El inicio de TARV debe ser aplazado para luego de la fase de inducción o diaria en el caso de la meningitis tuberculosa ${ }^{46}$. En el paciente en terapia antituberculosa existen situaciones especiales relacionadas a interacciones con la TARV y el creciente fenómeno de resistencia a los fármacos anti-tuberculosos de primera línea que se señalan en la Tabla $10^{1,47,48}$. Por último, las dosis correspondientes a cada fármaco se indican en la Tabla 11 .

\section{Infecciones por micobacterias no tuberculosas (MNT)}

\section{Diagnóstico}

Las micobacterias atípicas son agentes ubicuos y que no se transmiten de persona a persona a diferencia de $M$. tuberculosis. Las presentaciones clínicas más habituales en los pacientes seropositivos para VIH son las formas diseminadas y la pulmonar ${ }^{49-51}$. Para el diagnóstico de la infección diseminada es requisito aislar el agente en sangre, nódulos linfáticos, médula ósea u otros fluidos estériles, y para la infección pulmonar se deben seguir los criterios definidos por la ATS/IDSA del año $2007^{51}$ (Tabla 12).

\section{Infección por Mycobacterium avium complex (MAC)}

\section{Diagnóstico}

Es la infección sistémica multifocal más frecuente en el paciente infectado por VIH con grave inmunosupre-

\begin{tabular}{|c|c|c|}
\hline Situación clínica & Esquema vo: Primera ocasión y/o agente multisensible & Duración \\
\hline TBC latente & HIN (300 mg/día) + piridoxina* o RFP (600 mg) & $\begin{array}{l}\text { HIN: nueve meses } \\
\text { RFP: cuatro meses }\end{array}$ \\
\hline $\begin{array}{l}\text { TBC pulmonar } \\
\left.\text { (Con linf. TCD4 > } 100 \text { céls } / \mathrm{mm}^{3}\right)\end{array}$ & $\begin{array}{l}\text { HIN-RFP-PZ-ETB /día por dos meses ( } 50 \text { dosis) } \\
\text { Mantención HIN-RFP } 3 \text { v/semana.por cuatro meses } \\
\text { La guía chilena señala: HIN-RFP } 2 \text { v/semana por } 4 \text { meses }\end{array}$ & Seis meses \\
\hline $\begin{array}{l}\text { TBC pulmonar } \\
\left(\text { Con linf. TCD4 }<100 / \mathrm{mm}^{3} \text { ) }\right. \\
\text { TBC pulmonar cavitada en cualquier estado inmunitario } \\
\text { TBC extra-pulmonar SIN compromiso de SNC, } \\
\text { pericardio, hueso o articulación }\end{array}$ & $\begin{array}{l}\text { HIN-RFP-PZ-ETB /día por } 2 \text { meses ( } 50 \text { dosis) } \\
\text { Mantención HIN-RFP } 3 \text { v/semanas por } 7 \text { meses } \\
\text { La guía chilena señala: HIN-RFP } 2 \text { v/semana por } 4 \text { meses }\end{array}$ & Nueve meses \\
\hline $\begin{array}{l}\text { TBC extra-pulmonar CON compromiso de SNC, pericar- } \\
\text { dio, hueso o articulación }\end{array}$ & $\begin{array}{l}\text { HIN-RFP-PZ-ETB /día por tres meses ( } 84 \text { dosis) } \\
\text { La guía chilena señala: dos meses } \\
\text { Mantención HIN-RFP } 3 v / \text { semanas por nueve meses } \\
\text { La guía chilena señala: HIN-RFP } 2 \text { v/semana pero el tiempo podría prolongarse según el caso } \\
\text { En TBC meníngea uso de corticosteroides por } 6 \text { semanas; en TBC pericárdica por } 11 \text { semanas** } \\
\text { El inicio de TARV debe ser aplazado para luego de la fase de inducción en la meningitis TBC }\end{array}$ & 12 meses \\
\hline
\end{tabular}




\begin{tabular}{|c|c|}
\hline Situación & Acción recomendada \\
\hline Necesidad de partir TARV en paciente naïve & $\begin{array}{l}\text { Se puede iniciar TARV concomitantemente prescindiendo del uso de IP. } \\
\text { En el caso de TBC meníngea, esperar al fin de la fase de inducción }\end{array}$ \\
\hline Necesidad de partir TARV con un IP & $\begin{array}{l}\text { Terapia antituberculosa no debe incluir RFP } \\
\text { Alternativas para la fase de inducción son moxifloxacina y levofloxacina, en } \\
\text { fase trisemanal uso de HIN-ETB-PZ }\end{array}$ \\
\hline Falla de tratamiento esquema empírico & $\begin{array}{l}\text { Inducción: diaria por seis meses } \\
\text { Aminoglucósido (kanamicina o amikacina) } \\
\text { Etionamida } \\
\text { Fluoroquinolona (moxifloxacina o levofloxacina) } \\
\text { ETB } \\
\text { PZ } \\
\text { Mantención: diaria por } 12 \text { a } 18 \text { meses con: } \\
\text { Igual esquema de inducción sin aminoglucósidos }\end{array}$ \\
\hline Resistencia a HIN & $\begin{array}{l}\text { Inducción } \\
\text { RFP, ETB y PZ diario por seis meses } \\
\text { Mantención } \\
\text { RFP y ETB diario por seis meses }\end{array}$ \\
\hline Resistencia a RFP & $\begin{array}{l}\text { Inducción: Diario por dos meses } \\
\text { HIN, ETB, PZ y fluroquinolona (moxifloxacina y levofloxacina). } \\
\text { Mantención: Diario por } 10 \text { meses } \\
\text { HIN, ETB y Fluroquinolona (moxifloxacina y levofloxacina) }\end{array}$ \\
\hline TBC multi-resistente ( $\mathrm{R}$ a HIN y RFP) & $\begin{array}{l}\text { Inducción: diario por } 6 \text { meses } \\
\text { PZ y ETB } \\
\text { Agente inyectable (aminoglucóosido) } \\
\text { Fluoroquinolona } \\
\text { Y al menos dos de los siguientes agentes: } \\
\text { PAS-etionamida o cicloserina } \\
\text { Mantención: Diario por } 12 \text { a } 18 \text { meses } \\
\text { Idem pero sin agente inyectable }\end{array}$ \\
\hline $\begin{array}{l}\text { TBC extensamente resistente (resistencia a HIN,RFP, fluoro- } \\
\text { quinolona y al menos un agente inyectable) }\end{array}$ & $\begin{array}{l}\text { Elaborar esquema ajustado de acuerdo a la sensibilidad específica y caracterís- } \\
\text { ticas particulares de paciente. Discutirlo con especialistas en TBC e Infectología }\end{array}$ \\
\hline
\end{tabular}

\begin{tabular}{|c|c|c|}
\hline Fármaco & Diaria vo: por peso (dosis habitual) & Trisemanal vo (dosis habitual) \\
\hline Isoniacida & 5 mg/kg (300 mg) & 15 mg/kg/día (800mg) \\
\hline Rifampicina & 10 mg/kg (600 mg) & 10 mg/kg/día (600mg) \\
\hline Etambutol & 20 mg/kg (800-1.600 mg) & 30 mg (1.200-2.400 mg) \\
\hline Pirazinamida & $25 \mathrm{mg} / \mathrm{kg}(1.000-2.000 \mathrm{mg})$ & $35 \mathrm{mg} / \mathrm{kg} / \mathrm{día}(1.500-3.000 \mathrm{mg})$ \\
\hline Estreptomicina, amikacina, kanamicina & 15 mg/kg (750-1.000 mg) & $25 \mathrm{mg} / \mathrm{kg}(1.000 \mathrm{mg}-1.500 \mathrm{mg})$ \\
\hline Etionamida & $10-20$ mg/kg (500-750 mg) & ND \\
\hline Cicloserina & $10-15$ mg/kg (500-750 mg) & ND \\
\hline Moxifloxacina & 400 mg/día & ND \\
\hline Levofloxacina & 500 a 1.000 mg/día & ND \\
\hline PAS* & 8-12 g/día (dividir en tres tomas) & ND \\
\hline
\end{tabular}


sión. Se caracteriza por fiebre prolongada, sudoración, baja de peso, diarrea y dolor abdominal. Suele focalizar más cuando se asocia a SRI y puede incluir linfadenitis, neumonitis, pericarditis, osteomielitis, compromiso de tubo digestivo, abscesos en piel y tejidos blandos, úlceras genitales y lesión del $\mathrm{SNC}^{52}$. Tiene anomalías de laboratorio clásicas: anemia grave, incremento de SGOT y SGPT discreto con importante elevación de FA y GGT ( $>10$ veces el valor máximo normal) en especial cuando se asocian a SRI ${ }^{52,53}$.

\section{Tratamiento}

$\mathrm{Su}$ terapia específica se señala en la Tabla 13. Claritromicina asociada a etambutol es el tratamiento de elección $(\mathrm{AI})^{54-56}$, con o sin adición de RFP, el cual debe ser prolongado: 12 meses al menos ${ }^{57}$. Azitromicina es la alternativa a claritromicina en caso de contraindicación $(\mathrm{AI})^{58}$. Quinolonas y aminoglucósidos son también fármacos alternativos. Todos estos pacientes deben partir con TARV después de haber completado dos semanas de tratamiento para disminuir el riesgo de SRI grave asociado a MAC.

\section{Infección por Mycobacterium kansasii}

$\mathrm{Su}$ hallazgo en el paciente con infección por VIH, sin excepción, representa una infección activa. Hay que

Tabla 12. Criterios diagnósticos de la infección pulmonar
por Mycobacterium no tuberculoso

recordar que $M$. kansasii tiene resistencia intrínseca a PZ en $100 \%$ de las veces y pueden tener resistencia in vitro a HIN (CIM: $>1 \mu \mathrm{g} / \mathrm{mL}$ ) en 70 a $85 \%$ de cepas aisladas ${ }^{50}$. El tratamiento debe mantenerse 12 meses luego de tener cultivos negativos y en general se prolonga por $18 \mathrm{me}-$ $\operatorname{ses}^{50,59}$ (Tabla 14).

\section{Otras micobacterias no tuberculosas}

Existen una variedad importante de MNT que infectan al paciente con infección por VIH que, si bien son inha-

\begin{tabular}{|c|c|c|}
\hline & Esquema (toma diaria vo) & Duración \\
\hline Diseminada no pulmonar & $\begin{array}{l}\text { Claritromicina } 500 \mathrm{mg} \mathrm{c} / 12 \mathrm{~h} \\
\text { Etambutol } 15 \mathrm{mg} / \mathrm{kg} / \mathrm{dí} \text { a }\end{array}$ & 12 meses \\
\hline Pulmonar cavitada, bronquiectasias o nodular & $\begin{array}{l}\text { Claritromicina } 500 \mathrm{mg} \mathrm{c} / 12 \mathrm{~h} \\
\text { Etambutol } 15 \mathrm{mg} / \mathrm{kg} / \mathrm{día} \\
\text { Rifampicina } 600 \mathrm{mg} / \mathrm{día}\end{array}$ & 12 a 18 meses \\
\hline Contraindicación de claritromicina & $\begin{array}{l}\text { Azitromicina } 500 \mathrm{mg} / \mathrm{día} \\
\text { Etambutol } 15 \mathrm{mg} / \mathrm{kg} / \mathrm{día}\end{array}$ & 12 meses \\
\hline Riesgo de resistencia o mortalidad* & $\begin{array}{l}\text { Claritromicina } 500 \mathrm{mg} \mathrm{c/12} \mathrm{h}+\text { etambutol } 15 \mathrm{mg} / \mathrm{kg} / \mathrm{día} \text { + rifampicina } 600 \mathrm{mg} / \text { día y amikacina 10-15 mg/ } \\
\text { día iv O levofloxacina } 500 \mathrm{mg} / \mathrm{día} \text { O ciprofloxacina } 500-750 \mathrm{mg} \mathrm{c/12} \mathrm{h}\end{array}$ & 12 meses \\
\hline Falla terapeútica** & $\begin{array}{l}\text { Similar esquema de riesgo de resistencia o mortalidad incluyendo claritromicina o azitromicina, siempre que } \\
\text { antibiograma demuestre sensibilidad }\end{array}$ & 12 a 18 meses \\
\hline
\end{tabular}

\begin{tabular}{|c|c|c|}
\hline & Esquema (toma diaria vo) & Duración \\
\hline Primera elección & Rifampicina $600 \mathrm{mg} / \mathrm{día}$ + etambutol $15 \mathrm{mg} / \mathrm{kg}$ día + claritromicina $500 \mathrm{mg} \mathrm{c/12} \mathrm{h}$ * & 18 meses \\
\hline Alternativas & Rifampicina $600 \mathrm{mg} / \mathrm{día}$ + etambutol $15 \mathrm{mg} / \mathrm{kg}$ día + isoniacida $300 \mathrm{mg} /$ día + piridoxina 50 mg/día & 18 meses \\
\hline Alergia o contraindicación de rifampicina & $\begin{array}{l}\text { Isoniacida } 300 \mathrm{mg} / \mathrm{día}+\text { piridoxina } 50 \mathrm{mg} / \mathrm{d} \text { á + etambutol } 15 \mathrm{mg} / \mathrm{kg} / \mathrm{día} \text { + claritromicina } 500 \mathrm{mg} \mathrm{c} / 12 \mathrm{~h} \\
+ \text { sulfametoxazol } 1 \mathrm{gc} / 8 \mathrm{~h}\end{array}$ & 18 meses \\
\hline
\end{tabular}


Tabla 15. Tratamiento de otras micobacterias no tuberculosas

\begin{tabular}{|c|c|c|c|}
\hline Micobacteria & Esquema de elección & Duración & Observaciones \\
\hline M. abscessus (MRC) & $\begin{array}{l}\text { Piel, tejido blando y hueso: Claritromicina } 500 \text { mg c/12 h vo + amika- } \\
\text { cina } 15 \mathrm{mg} / \mathrm{kg} / \text { día iv }+ \text { imipenem } 500 \mathrm{mg} \mathrm{c/12} \mathrm{h} \mathrm{iv} \\
\text { Pulmón: No existe esquema de elección } \\
\text { Inicial por } 4 \text { meses: claritromicina } 500 \mathrm{mg} \mathrm{c/12} \mathrm{h} \mathrm{vo} \mathrm{+} \mathrm{amikacina} 15 \\
\text { mg/kg/día iv + imipenem } 500 \mathrm{mg} \mathrm{c/12} \mathrm{h} \mathrm{iv} \\
\text { Mantención } 10 \text { meses }\end{array}$ & $\begin{array}{l}\text { Cuatro a seis meses } \\
\text { Catorce meses o supre- } \\
\text { sión crónica }\end{array}$ & $\begin{array}{l}\text { Tener un antibiograma en todos los casos } \\
\text { Pensar en apoyo quirúrgico y terapia de supre- } \\
\text { sión intermitente en pulmón }\end{array}$ \\
\hline M. fortuitum (MRC) & $\begin{array}{l}\text { Cotrimoxazol } 10 \mathrm{mg} \mathrm{T} / \mathrm{kg} / \mathrm{día} \text { vo + claritromicina } 500 \mathrm{mg} \mathrm{c/12} \mathrm{h} \mathrm{vo} \\
\text { Imipenem o amikacina en caso de resistencia a claritromicina }\end{array}$ & $\begin{array}{l}\text { Cuatro a seis meses loca- } \\
\text { lización no pulmonar } \\
12 \text { meses en pulmón }\end{array}$ & $\begin{array}{l}\text { Asociado a reflujo gastroesofágico. } \\
\text { Ocurre en tejidos blandos, hueso y pulmón }\end{array}$ \\
\hline M. chelonae (MRC) & Claritromicina 500 mgc/12 h vo + levofloxacina 500 mg/día vo & $\begin{array}{l}\text { Seis meses en hueso y } 12 \\
\text { meses en pulmón }\end{array}$ & $\begin{array}{l}\text { En keratitis, piel, tejido blando y pulmón } \\
\text { (menos frecuente). Apoyo con antibiograma }\end{array}$ \\
\hline M. genavense & $\begin{array}{l}\text { Claritromicina } 500 \mathrm{mg} \mathrm{c} / 12 \mathrm{~h} \text { vo + rifampicina } 600 \mathrm{mg} \mathrm{c/12} \mathrm{h} \mathrm{vo} \mathrm{+} \\
\text { levofloxacina } 500 \mathrm{mg} / \text { día vo }\end{array}$ & 12 meses & $\begin{array}{l}\text { Crecimiento lento. Pensar en sospecha de } \\
\text { MAC con cultivos negativos }\end{array}$ \\
\hline M. gordonae & $\begin{array}{l}\text { Rifampicina } 600 \text { mg /día vo + etambutol } 15 \text { mg/kg/día vo + claritro- } \\
\text { micina o ciprofloxacina }\end{array}$ & Seis a 12 meses & Diseminado y pulmonar \\
\hline M. haemophilum & $\begin{array}{l}\text { Claritromicina } 500 \text { mg c/12 h vo + rifampicina } 600 \text { mg/ día vo + cipro- } \\
\text { floxacina } 500 \mathrm{mg} \mathrm{c/12} \mathrm{h} \mathrm{vo}\end{array}$ & Seis a 12 meses & $\begin{array}{l}\text { Infección diseminada y en sitios fríos en } \\
\text { especial pies. }\end{array}$ \\
\hline M. inmunogenum (MRC) & Claritromicina 500 mg c/12 h vo + amikacina 15 mg/kg/día iv & Seis a 12 meses & En piel, cornea, rodilla, CVC, sangre y pulmón. \\
\hline M. malmoense & $\begin{array}{l}\text { Isoniacida } 300 \mathrm{mg} / \text { día vo + rifampicina } 600 \mathrm{mg} / \text { día vo + etambutol } \\
1.200 \mathrm{mg} / \text { día vo + claritromicina } 500 \mathrm{mg} \mathrm{c} / 12 \mathrm{~h} \text { vo }\end{array}$ & Seis a 12 meses & Infección de pulmon y ganglios linfáticos \\
\hline M. marinum & $\begin{array}{l}\text { Etambutol } 1200 \text { mg/ día vo + claritromicina } 500 \text { mg c/12 h vo + } \\
\text { rifampicina } 600 \text { mg/día vo }\end{array}$ & $\begin{array}{l}3-4 \text { meses } \\
6 \text { o }>\text { meses para hueso }\end{array}$ & $\begin{array}{l}\text { Produce "granulomas de piscina", comprome- } \\
\text { te piel y hueso }\end{array}$ \\
\hline M. mucogenicum (MRC) & $\begin{array}{l}\text { Claritromicina } 500 \mathrm{mg} \mathrm{c} / 12 \mathrm{~h}+\text { cotrimoxazol } 10 \mathrm{mg} \mathrm{T} / \mathrm{kg} / \text { día vo }+ \\
\text { levofloxacina } 500 \mathrm{mg} / \text { día vo }\end{array}$ & Cuatro - seis meses & Infección relacionada con CVC \\
\hline M. scrofulaceum & Claritromicina 500 mg c/12 h vo + etambutol 1.200 mg/día vo & Cuatro-seis meses & Nódulos linfáticos \\
\hline M. ulcerans & Etambutol $1.200 \mathrm{mg} /$ día vo + cotrimoxazol:10 mg T/kg/día vo & Cuatro-seis semanas & Ulceras cutáneas \\
\hline
\end{tabular}

bituales, cuando se presentan son un desafío terapéutico. En la Tabla 15 se señalan los principales agentes, localizaciones y tratamientos respectivos ${ }^{49,51,52}$.

\section{Infecciones bacterianas/sífilis/Bartonella sp}

\section{Infecciones bacterianas respiratorias}

\section{Diagnóstico}

Las infecciones bacterianas respiratorias son dos a tres veces más frecuentes en el paciente infectado con VIH y representan con frecuencia el debut de la etapa $\operatorname{SIDA}^{60}$. Las consideraciones respecto al agente etiológico, diagnóstico y tratamiento son prácticamente las mismas de los pacientes inmunocompetentes, con algunas diferencias relevantes. Hay mayor incidencia de bacteriemia en la neumonía adquirida en la comunidad (NAC) por Strepto- coccus pneumoniae, (>100 veces) ${ }^{61,62}$ es más frecuente la presencia de Pseudomonas aeruginosa y Staphylococcus aureus y los microorganismos atípicos como Legionella spp, Mycoplasma pneumoniae y Chlamydia spp, son inhabituales, lo que debe considerarse el momento de las decisiones terapéuticas ${ }^{63-65}$. Debe hacerse el mayor esfuerzo por definir el agente etiológico, dada la mayor incidencia de TBC y la capacidad de co-infeccción con otros agentes que es más frecuente en el paciente seropositivo para VIH. Es imprescindible realizar tinción de Gram y cultivo de la expectoración y tomar hemocultivos.

\section{Tratamiento}

Los criterios clínicos para catalogar la NAC corresponden a las normas del Ministerio de Salud (MINSAL), las que definen tres escenarios, basadas en las guías británicas de manejo de NAC ${ }^{66}$. Los $\beta$-lactámicos asociados a macrólidos son la terapia de elección ${ }^{1}$ (AI) (Tabla 16). El 


\begin{tabular}{|c|c|c|}
\hline Situación clínica* & Terapia de elección & $\begin{array}{l}\text { Alternativas (alérgicos o uso de } \beta \text {-lactámicos los últimos } \\
\text { tres meses) }\end{array}$ \\
\hline Neumonía con manejo ambulatorio & Amoxicilina o amoxicilina/ác. clavúlanico + claritromicina 500 mg c/12 h vo & Levofloxacina 750 mg/día/vo \\
\hline $\begin{array}{l}\text { Neumonía que requiere hospitaliza- } \\
\text { ción no UCl }\end{array}$ & $\begin{array}{l}\text { Ceftriaxona } 2 \mathrm{~g} / \text { día iv, cefotaxima } 1 \mathrm{~g} \text { c/8 h iv o ampicilina/sulbactam } 1,5 \mathrm{~g} \\
\mathrm{c} / 8 \mathrm{~h} \text { iv + claritromicina } 500 \mathrm{mg} \mathrm{c/12} \mathrm{h} \mathrm{vo}\end{array}$ & Levofloxacina 750 mg/día iv o moxifloxacina 400 mg iv \\
\hline Neumonía que requiere $\mathrm{UCl}$ & $\begin{array}{l}\text { Ceftriaxona } 2 \mathrm{~g} / \text { día iv, cefotaxima } 1 \mathrm{~g} \text { c/8 h iv o ampicilina/sulbactam 1,5 g } \\
\mathrm{c} / 8 \mathrm{~h} \text { iv }+ \text { levofloxacina } 750 \mathrm{mg} \text { iv }\end{array}$ & Levofloxacina 750 mg/día iv o moxifloxacina 400 mg iv \\
\hline
\end{tabular}

\begin{tabular}{|c|c|c|}
\hline Agente & Terapia de elección & Alternativa* \\
\hline Salmonelosis & $\begin{array}{l}\text { Ciprofloxacina } 400 \mathrm{mg} \text { c/12 h iv } 0500-750 \mathrm{mg} \mathrm{c} / 12 \mathrm{~h} \text { vo } \\
\text { Duración: gastroenteritis leve } 7 \text { a } 10 \text { días. } \\
\text { gastroenteritis con bacteriemia y L-CD4 }>200 \text { céls } / \mathrm{mL} 14 \text { días. } \\
\text { gastroenteritis con bacteriemia, L-CD4 }<100 \text { céls } / \mathrm{mL} \text { o localización extra-intestinal } \\
2 \text { a } 6 \text { semanas }\end{array}$ & $\begin{array}{l}\text { Ceftriaxona } 2 \mathrm{~g} / \text { día iv O cefotaxima } 1 \mathrm{~g} \text { c/8 h seguido de } \\
\text { levofloxacina } 750 \mathrm{mg} / \text { día vo o moxifloxacina } 400 \mathrm{mg} / \mathrm{día} \\
\text { vo en duración similar al esquema de elección }\end{array}$ \\
\hline Shigelosis & $\begin{array}{l}\text { Ciprofloxacina iv o vo en igual dosis que en salmonelosis } \\
\text { Duración: gastroenteritis: } 3-7 \text { días } \\
\text { bacteriemia: } 14 \text { días }\end{array}$ & $\begin{array}{l}\text { Azitromicina } 500 \mathrm{mg} / \text { día vo por } 5 \text { días (No es una tera- } \\
\text { pia suficiente para bacteriemia) }\end{array}$ \\
\hline Campilobacteriosis & $\begin{array}{l}\text { Ciprofloxacina } 500 \text { mg c/12 h vo O azitromicina } 500 \text { mg/día vo } \\
\text { Duración: leve a moderada } 7 \text { días } \\
\text { grave con bacteriemia } 14 \text { días (considerar agregar aminoglucósidos) }\end{array}$ & \\
\hline
\end{tabular}

tratamiento debe ajustarse al agente etiológico aislado. Si la etiología es $S$. aureus, son opciones válidas clindamicina, vancomicina o linezolid. En el caso de P. aeruginosa, cefoperazona/sulbactam, imipenem o meropenen + levofloxacina, ciprofloxacina o aminoglucósidos. La duración de la terapia dependerá de los criterios clínicos asociados, no debiendo ser nunca menor a una semana y siempre de dos semanas o más en el caso de bacteriemia asociada.

\section{Infecciones bacterianas entéricas}

\section{Diagnóstico}

Los agentes etiológicos son, en general, los mismos que en el individuo inmunocompetentes pero su incidencia es mayor (20 a 100 veces) que en el paciente no portador de $\mathrm{VIH}^{67}$. Pueden ser leves y auto-limitadas o asociarse a un síndrome disentérico, con fiebre, diarrea sanguinolenta, baja de peso y bacteriemia. Pueden tener, además, localizaciones extra-intestinales y manifestarse como fiebre prolongada e incluso meningitis ${ }^{68,69}$. Tienen mal pronóstico si se asocian a intensa inmunosupresión con recuento de linfocitos T-CD4 inferior a 100 céls $/ \mathrm{mL}$ y las recaídas son más frecuentes especialmente en la salmonelosis.

El diagnóstico se establece por coprocultivo y hemocultivos. La colonoscopia puede demostrar lesiones ulceradas similares a las producidas por citomegalovirus (CMV).

\section{Tratamiento}

Las principales causas de diarrea bacteriana y su tratamiento se señalan en la Tabla 17. Las fluoroquinolonas, y en especial ciprofloxacina, son el tratamiento de elección $^{70}$ (AIII). Azitromicina y las cefalosporinas de tercera generación representan una alternativa.

\section{Sifilis y neurolúes}

\section{Diagnóstico}

Sífilis primaria: Infección aguda con lesión ulcerada genital y/o oral única o múltiple + VDRL positivo en sangre $^{71}$.

Sífilis secundaria: Ocurre dos a ocho semanas después de la sífilis primaria. Hay compromiso cutáneo maculopapular, nodular-escamoso o pustular, potencialmente en toda la piel y que afecta palmas y plantas, fiebre, linfadenopatías, cefalea, mialgias y artralgias, con o sin condiloma lata + VDRL positivo. Las pruebas treponémicas MHA-TP o FTA-ABS deben ser positivas en sangre pero, ante un examen negativo o la imposibilidad de hacerlo, no se debe limitar el tratamiento ${ }^{71,72}$. 
Sífilis latente temprana: Más de 1 año y menos de 4 años desde el evento de sífilis primaria o secundaria, pueden recurrir síntomas de sífilis secundaria y no debe tener elementos de etapa latente tardía. Los marcadores (VDRL + MHA-TP o FTA-ABS) son positivos ${ }^{71,72}$.

Síflis latente tardía: Afecta a los sistemas cardiovascular, neurológico (compromiso meníngeo, meningo-vascular y/o parenquimatosas) o produce lesiones gomosas en cualquier órgano y se acompaña de VDRL + MHA-TP o FTA-ABS positivos en sangre ${ }^{71,72}$.

Neurosífilis: Puede ocurrir en cualquier etapa de la enfermedad. Debe prestarse atención a la rigidez de nuca, cefalea, fiebre, compromiso ocular (uveítis) y lesión de $\mathrm{VII}^{\circ}$ par craneal, pero puede ser asintomático ${ }^{73}$. Requiere presencia de VDRL positivo en sangre y LCR con prueba treponémica (FTA-ABS o MHA-TP) positiva en sangre. Hay alteración de LCR con $>10$ céls $/ \mathrm{mm}^{3}$, incremento de las proteínas y leve descenso de glucosa, pero el LCR también puede ser normal. La PL debe realizarse en todo paciente con manifestaciones de sífilis tardía y también se recomienda en infección por VIH asintomáticos con $<350$ de linfocitos T-CD4 $/ \mathrm{mm}^{3}$ y VDRL o RPR $>$ o $=1: 32$ en sangre $^{72,74}$; sin embargo, en pacientes infectados por VIH se puede hallar neurosífilis con diluciones más bajas que la señalada ${ }^{73}$. Los pacientes con VDRL o RPR positivo en sangre y análisis citoquímico de LCR alterado ( $>10$ céls/ $\mathrm{mm}^{3}$, proteínas elevadas y glucosa baja) + VDRL negativo en LCR deben tratarse como neurosífilis ${ }^{74}$.

La visión de campo oscuro de muestras provenientes de lesiones ulceradas genitales (chancro) o pápulas secundarias es una opción válida para el diagnóstico pero de uso inhabitual en la práctica diaria.

\section{Tratamiento}

El antimicrobiano de elección sigue siendo penicili$\mathrm{na}^{72,74}$ (AII). Ante el uso de terapia alternativa a penicilina (ceftriaxona o doxiciclina) se debe vigilar al paciente clínicamente y con pruebas no treponémicas seriadas para confirmar su curación ${ }^{75}$ (Tabla 18). Debe mantenerse un control con VDRL en sangre al mes, 3, 6, 12 y 24 meses, que además guarda un correlato de respuesta directo cuando enfrentamos casos de neurosífilis ${ }^{76}$. La curación se confirma con un descenso $>$ de 4 diluciones de VDRL o RPR en transcurso de 12 meses. La penicilina benzatina no atraviesa la barrera hemato-encefálica y no es una opción para el tratamiento de la neurosífilis ${ }^{72,74,77}$, la que debe tratarse con penicilina iv en dosis altas.

\section{Bartonelosis}

\section{Diagnóstico}

La bartonelosis representa la infección por Bartonella quintana o B. henselae. El agente causal se puede sospechar por antecedentes epidemiológicos. Habitualmente B. quintana ocurre en estratos socio-económicos bajos, vagabundos, alcohólicos y con pediculosis corporal. Sus manifestaciones clínicas son angiomatosis bacilar, compromiso óseo y subcutáneo. En cambio, B. henselae se asocia a la mordedura o arañazo de gato. Puede presentarse como una enfermedad por arañazo de gato o puede tener manifestaciones extra ganglionares como peliosis hepática y endocarditis ${ }^{78}$. La peliosis hepática tiene características propias en la TAC de abdomen como son la formación de lagos vasculares hepáticos, hipodensos, de 1 a $5 \mathrm{~cm}$ de diámetro, con captación ocasional de contraste y sin efecto de masa $^{79}$. El diagnóstico se establece por estudio anátomo-patológico de la lesión, la que debe diferenciarse principalmente del sarcoma de Kaposi. Se confirma mediante serología IgG cuantitativa (sensibilidad 90-97\%) y RPC en tejido (sensibilidad $100 \%$ ) $^{1,78}$. La endocarditis por bartonela se acompaña de títulos de anticuerpos $>1: 800^{50}$.

\section{Tratamiento}

El manejo de la bartonelosis se expone en la Tabla 19. Doxiciclina y eritromicina son la terapia de elección ${ }^{1,78,80}$ (AII). Para las infecciones graves es necesario emplear doxiciclina iv, difícil de conseguir en Chile; se puede recurrir como alternativa, a ceftriaxona en altas dosis ${ }^{50}$.

Tabla 18. Tratamiento de la sífilis en el paciente con infección por VIH

\section{Estado de enfermedad}

Primaria o chancro sifilítico

Secundaria o latente

Latente tardía sin neurosífilis

Neurosífilis
Terapia de elección

Penicilina benzatínica 2.400.000 UI por 1 vez im
Alternativa para alergia a penicilina

Ceftriaxona $1 \mathrm{~g}$ im por $1 \mathrm{vez}$

Azitromicina $2 \mathrm{~g}$ por $1 \mathrm{vez}$

Doxiciclina 200 mg / día por 7 días

Penicilina benzatínica 2.400.000 UI 1 vez por semana por 3 semanas im

Penicilina benzatínica 2.400.000 UI 1 vez por semana por 3 semanas im

Penicilina cristalina 18 a 24 millones diarios por 14 días (3-4 millones c/4h) iv
Doxicilina $200 \mathrm{mg} /$ día por 14 días vo Cefrtiaxona $1 \mathrm{~g}$ im o iv por 10 días

Doxiciclina $100 \mathrm{mg} \mathrm{c} / 12 \mathrm{~h}$ por 28 días vo

Ceftriaxona $2 \mathrm{~g} /$ día iv por 14 días Debe intentarse desensibilización de PNC 


\begin{tabular}{|c|c|c|}
\hline Situación clínica & Terapia de elección & Alternativa \\
\hline $\begin{array}{l}\text { Angiomatosis bacilar, peliosis hepática, } \\
\text { bacteremia y osteomielitis }\end{array}$ & $\begin{array}{l}\text { Claritromicina } 500 \mathrm{mg} \mathrm{c} / 12 \mathrm{~h} \text { vo } \\
\text { Doxiciclina } 100 \mathrm{mg} \mathrm{c} / 12 \mathrm{~h} \text { vo o iv o eritromicina } 500 \mathrm{mg} \mathrm{c} / 6 \mathrm{~h} \text { vo o iv por al menos } \\
\text { tres meses } \\
\text { Mantener supresión con claritromicina } 500 \mathrm{mg} \mathrm{c} / 12 \mathrm{~h} \text { hasta recuentos de LTCD4 } \\
>200 \text { céls } / \mathrm{mL}\end{array}$ & Claritromicina $500 \mathrm{mg}$ vo $\mathrm{c} / 12 \mathrm{~h}$ \\
\hline Endocarditis & $\begin{array}{l}\text { Ceftriaxona } 2 \mathrm{~g} / \mathrm{dia} \text { iv por seis semanas + doxiciclina } 100 \mathrm{c} / 12 \mathrm{~h} \text { vo o iv por seis semanas } \\
+ \text { gentamicina } 1 \mathrm{mg} / \mathrm{kg} / \mathrm{c} / 8 \mathrm{~h} \text { iv por } 14 \text { días* }^{*}\end{array}$ & No existe alternativas \\
\hline Infecciones graves o de SNC & $\begin{array}{l}\text { Doxiciclina } 100 \text { mg iv inicial y luego vo + rifampicina } 600 \text { mg/día por al menos cuatro } \\
\text { meses y luego seguir con terapia supresiva con claritromicina }\end{array}$ & $\begin{array}{l}\text { Ceftriaxona } 2 \mathrm{~g} \mathrm{c} / 12 \mathrm{~h} \text { iv }+ \text { doxiciclina } \\
100 \mathrm{mg} \mathrm{c} / 12 \mathrm{~h}+\text { rifampicina } 600 \mathrm{mg} / \mathrm{dí} a\end{array}$ \\
\hline
\end{tabular}

\section{Infecciones parasitarias}

\section{Toxoplasmosis cerebral}

\section{Diagnóstico}

La toxoplasmosis cerebral (TC) se presenta en pacientes con intensa inmunodepresión; el grupo de mayor riesgo es de aquellos pacientes con recuento de linfocitos T-CD4 < 50 céls $/ \mathrm{mL}$ y es inusual encontrarla en aquellos con $>200$ linfocitos T-CD4 céls $/ \mathrm{mL}^{1}$. El diagnóstico se establece por un cuadro clínico compatible: cefalea, confusión, trastorno motor/sensitivo, crisis convulsivas y ocasionalmente fiebre. En la TAC de cerebro se pueden ver tres tipos de lesiones que ocurren en 1/3 de las veces cada una: lesiones solitarias, dos a cinco lesiones o múltiples lesiones. E1 90\% de los casos capta contraste en anillo, de modo regular ${ }^{81}$. El principal diagnóstico diferencial se realiza con el linfoma primario del SNC (LPSNC) que en 25 a $50 \%$ de las veces puede ser multicéntrico; sin embargo, las lesiones de la TC suelen ser más pequeñas, homogéneas, con captación de contraste regular y menos edema que las lesiones por LPSNC $^{82,83}$. La IgG para Toxoplasma gondii suele ser positiva, prácticamente en la totalidad de los pacientes infectados con VIH, de modo que observar un incremento en los títulos de esta inmunoglobulina respecto de un examen basal previo puede ser de utilidad. Es excepcional la TC en pacientes con IgG para Toxoplasma sp negativa debido a que esta $\mathrm{IO}$, en la mayoría de casos, obedece a una reactivación de una infección latente y por este hecho la IgM no es de utilidad. La RPC para T. gondii es altamente específica (96-100\%) pero su baja sensibilidad $(50 \%)$ limita su uso práctico y además, una vez que se ha instaurado el tratamiento se torna negativa rápidamente ${ }^{84,85}$. En la práctica habitual el diagnóstico se establece por la presentación clínica y las imágenes. Se parte con terapia, las lesiones suelen disminuir ostensiblemente o desaparecer en el lapso de dos a cuatro semanas. Ante la persistencia de lesiones se indicará biopsia cerebral estereotáxica y posterior estudio de la muestra de tejido con tinción con hematoxilina-eosina o inmunoperoxidasa. La RPC en LCR para virus de Epstein Barr y técnicas imagenológicas como la tomografía por emisión de fotones individuales (SPECT -de sus siglas en inglés-) o la tomografía por emisión de positrones (PET -de sus siglas en inglés-) ayudan a diferenciar la TC del LPSNC ${ }^{86,87}$.

\section{Tratamiento}

Clásica y de elección es la asociación de pirimetamina y sulfadiazina ${ }^{88-90}$ (A1) acompañadas de ácido folínico; sin embargo, existe evidencia reciente de igual eficacia y seguridad con el uso de cotrimoxazol ${ }^{1,92}$ (AII) (Tabla 20). Pirimetamina es el fármaco que mejor penetra al $\mathrm{SNC}^{93}$; por otra parte, cotrimoxazol es el único que posee presentación endovenosa y está disponible en nuestro país por lo que, para un paciente crítico con TC debería ser de elección. Importa además la cantidad de comprimidos diarios a tomar por el paciente, que podría llegar hasta 15 al día en los esquemas clásicos versus cuatro o seis si se emplea cotrimoxazol. El tratamiento alternativo consiste en pirimetamina conjuntamente con clindamicina, atovaquona o azitromicina.

\section{Infecciones parasitarias intestinales}

\section{Diagnóstico}

Son cada vez más inhabituales en nuestro medio, se asocian a intensa inmunosupresión, es fundamental el manejo hidro-electrolítico y es una indicación de inicio inmediato de $\mathrm{TARV}^{1,94}$. El diagnóstico se realiza con el copro-parasitario directo. La microsporidiosis, posiblemente la causa más frecuente de diarrea crónica en nuestro país, requiere una tinción especial tri-cromo modificada, sólo disponible en centros de referencia (ISP).

\section{Tratamiento}

Los principales agentes a cubrir son Criptosporidium spp, Isospora belli y Microsporidium. El primero de ellos 


\section{Tabla 20. Tratamiento de la toxoplasmosis cerebral}

Terapia (elección y alternativas)

Pirimetamina $200 \mathrm{mg} / \mathrm{d}$ vo inicial y desde $2^{\circ}$ día $50 \mathrm{mg} / \mathrm{d}(<60 \mathrm{~kg}$ ) a $75 \mathrm{mg} / \mathrm{d}$ (> $60 \mathrm{~kg}$ ) vo + sulfadiazina $1.000 \mathrm{mg}$

(2 tabletas de $500 \mathrm{mg}$ ) (<60 kg) a $1.500 \mathrm{mg}$ (3 tabletas de $500 \mathrm{mg}$ ) (> $60 \mathrm{~kg}$ ) vo cada 6 horas

Leucovorina (ácido folínico) 10 a $25 \mathrm{mg} / \mathrm{día}$

Pirimetamina y leucovorina igual indicación

Clindamicina $600 \mathrm{mg}$ vo $\mathrm{c} / 6 \mathrm{~h}$

Sulfametoxazol (50-75 mg/kg) trimetoprim (10-15 mg/kg) vo c/12 h vo

Manejo de pacientes graves

Sulfametoxazol (75 mg/ $/ \mathrm{kg}$ ) trimetoprim (15 mg/kg/día) c/8 h o c/6h iv

Clindamicina $600 \mathrm{mg} / 8$ horas vo

Pirimetamina y leucovorina igual indicación

Terapia de mantención

Pirimetamina 50 mg/día VO + sulfadiazina 30 mg/kg/día vo o sulfametoxazol 25 mg/kg/día + trimetoprim 5 mg/

$\mathrm{kg} / \mathrm{dí}$ vo

\section{Observaciones}

Duración seis semanas

$N^{\circ}$ de comprimidos diarios: entre 11 y 15

Duración seis semanas

Trabajo original considera uso de clindamicina oral

$\mathrm{N}^{\circ}$ de comprimidos diarios: 11

Duración 4 semanas

No de comprimidos diarios: 4

Se puede optar por cotrimoxazol oral una vez superada la fase crítica

\begin{tabular}{|c|c|c|}
\hline Agente & Terapia de elección & Alternativa \\
\hline Criptosporidiosis & No existe terapia específica recomendada & \\
\hline Isosporidiosis & Cotrimoxazol forte $(160 / 800 \mathrm{mg})$ c/6 h vo por $10-28$ días & $\begin{array}{l}\text { Pirimetamina } 50-75 \mathrm{mg} / \mathrm{d} / \mathrm{vo}+\text { leucovorina } 10-25 \mathrm{mg} / \mathrm{d} / \mathrm{vo} \\
\text { o ciprofloxacina } 500 \mathrm{mg} \mathrm{c} / 12 \mathrm{~h} \text { vo por igual tiempo }\end{array}$ \\
\hline $\begin{array}{l}\text { Microsporidiosis } \\
\text { Especies distintas de Enterocytozoon bienuesi }\end{array}$ & $\begin{array}{l}\text { Albendazol } 400 \mathrm{mg} \mathrm{c} / 12 \mathrm{~h} \text { vo continua hasta }>6 \text { meses con } \\
\text { linfocitos T-CD4 > } 200 \text { céls } / \mathrm{mL}\end{array}$ & $\begin{array}{l}\text { Enfermedad diseminada por Trachiteistopora o Anncallia } \\
\text { Itraconazol } 400 \text { mg/dia vo + albendazol } 400 \text { mg/día vo }\end{array}$ \\
\hline
\end{tabular}

\begin{tabular}{|c|c|c|}
\hline & Tratamiento elección * & Alternativa \\
\hline Sin compromiso SNC & $\begin{array}{l}\text { Benznidazole } 5-8 \mathrm{mg} / \mathrm{kg} / \mathrm{d} i ́ a \text { vo } \\
\text { c/12 h por 30-60 días }\end{array}$ & $\begin{array}{l}\text { Nifurtimox 8-10 } \mathrm{mg} / \mathrm{kg} / \mathrm{día} \text { por } \\
\text { 90-120 días }\end{array}$ \\
\hline Con compromiso de SNC & No definido & \\
\hline
\end{tabular}

y el más importante, carece de tratamiento. El fármaco de elección para la I. belli es cotrimoxazol (AI) ${ }^{1}$. Parásitos habituales como Entamoeba histolytica y Giardia lamblia responden a metronidazol o tinidazol. Loperamida es un tratamiento sintomático que puede ser de ayuda para el control más eficiente de la diarrea y el inicio de TARV ${ }^{1,94}$ (Tabla 21).

\section{Enfermedad de Chagas}

\section{Diagnóstico}

En el paciente con infección por VIH, la enfermedad de Chagas, representa una reactivación de una infección latente o crónica, asociada a altos niveles de parasitemia, inmunosupresión intensa (linfocitos T-CD4 < 200 céls/ $\mathrm{mL})$ o se presenta asociada a otras $\mathrm{IO}^{95,96}$.

Los pacientes portadores de VIH presentan, en $75 \%$ de los casos, manifestaciones del SNC como meningoencefalitis o masas cerebrales indistinguibles de la TC; 25 a $50 \%$ puede presentar miocarditis pero no suele ser el elemento inicial o más destacado del punto de vista clínico $^{95-97}$. El LCR demuestra pleocitosis de predominio linfocitario, con incremento de proteínas, y ocasionalmente presencia de tripomastigotes de Trypanosoma cruzi $^{96,97}$. El diagnóstico definitivo se establece por biopsia cerebral y por identificación directa del parásito en tejidos o en la sangre. La centrifugación de sangre o LCR mejora la sensibilidad de la visión directa. La RPC para T. cruzi en LCR sirve para monitorear la respuesta a tratamiento. Las pruebas serológicas son sensibles y específicas pero tienen con frecuencia falsos positivos y negativos ${ }^{96-98}$.

\section{Tratamiento}

Benznidazol es el tratamiento de elección y aunque el nivel de evidencia no es de suficiente potencia, es la mejor elección para lesiones del SNC ${ }^{1,97-99}$ (BIII). No se encuentra disponible en Chile. La alternativa es nifurti- 
$\operatorname{mox}^{1}$ (CII) (Tabla 22). La TARV debe iniciarse una vez estabilizado el paciente, es importante señalar que no existe información respecto de interacciones entre TARV y terapia contra T. cruzi.

\section{Infecciones virales}

\section{Infección por virus herpes simplex tipos 1 y 2}

\section{Diagnóstico}

Las infecciones herpéticas son habituales, en especial en la cavidad oral (VHS-1) y región genital (VHS-2). Son úlceras superficiales grandes y confluentes, dolorosas, pueden estar cubierta de detritus o fibrina, lo que les otorga una apariencia blanquecina amarillenta sucia y plana. En la boca se debe realizar el diagnóstico diferencial con la candidiasis orofaríngea que cursa con lesiones solevantadas, blancas, con aspecto de leche cortada; y con las aftas inflamatorias que son mucho más frecuentes, pequeñas, no confluentes y múltiples. En la práctica clínica diaria, el diagnóstico se establece mediante la visión directa de un operador con experiencia. Las lesiones herpéticas suelen reaparecer en el mismo sitio y ocasionalmente comprometen el área roja externa de los labios, situación que no ocurre con las aftas. Las lesiones genitales se asocian a dolor, linfadenopatía y pueden tener descarga uretral ocasionalmente. Lesiones ulceradas grandes y confluentes, tanto en boca como genitales, pueden verse en pacientes con recuento de linfocitos T-CD $4<100$ céls $/ \mathrm{mL}^{1}$. Los cultivos y las técnicas de biología molecular para el diagnóstico de estas lesiones se realizan sólo en algunos centros en Chile.

La queratitis, hepatitis y necrosis retinal aguda por VHS tienen similar incidencia que en el hospedero inmunocompetente, al igual que la encefalitis herpética que es esporádica y muy grave ${ }^{100,100 a}$. El diagnóstico de encefalitis herpética incluye compromiso agudo o subagudo del nivel de conciencia, alteración de funciones mentales superiores, fiebre, cefalea y convulsiones. En la tomografía computada de cerebro suelen encontrarse precozmente áreas isquémicas bilaterales, temporo-parietales, pero puede comprometerse cualquier zona cortical. El EEG está alterado en más de $90 \%$ de los pacientes y demuestra actividad epileptiforme y lentitud generalizada en ritmo de base. En el LCR hay pleocitosis linfocitaria, incremento de proteínas, discreta disminución de glucosa, presencia de eritrocitos, en más de $60 \%$ de los pacientes, incremento de ADA y el diagnóstico definitivo se establece mediante la confirmación del VHS tipo 1 ó 2 mediante RPC ${ }^{101}$. El tratamiento debe ser lo más precoz posible ya que el pronóstico está directamente relacionado al tiempo que tarda el inicio de la terapia específica.

\section{Tratamiento}

El fármaco de elección es aciclovir, tanto para lesiones leves, recurrentes, localizaciones no cutáneas como para encefalitis $^{101-103}$ (AII). Tabla 23. Ante las recidivas de lesiones muco-cutáneas se puede aplicar imiquimod al $5 \%$ que retarda la recurrencia y, en casos de recidivas de herpes genital, se puede emplear valaciclovir ${ }^{104,105}$. Foscarnet es la terapia de elección en los casos excepcionales de resistencia. Su disponibilidad es limitada en Chile.

\section{Herpes zoster}

\section{Diagnóstico}

El herpes zoster o zona representa una reactivación de una infección latente por virus varicela-zoster. La primoinfección (varicela) aparece clásicamente primero en cabeza, después en tronco y finalmente en extremidades, en una evolución rápida de 12 a $48 \mathrm{~h}$. El patrón de lesiones es ampliamente conocido con máculas, vesículas y costras que se observan simultáneamente.

Herpes zoster dermatómico. Se suele ver en pacientes que debutan con una IO o en aquellos que parten TARV dentro de un SRI, es doloroso, compromete uno o más dermatomas, las lesiones son eritematosas-violáceas, con presencia de vesículas que confluyen y posteriormente evolucionan a costras. El diagnóstico es clínico y puede recurrir en el tiempo siendo su principal complicación la neuralgia post-herpética que ocurre en 10 a $15 \%$ de los pacientes ${ }^{106}$. La neumonía asociada a herpes zoster es una complicación que se puede ver en el paciente con infección por VIH ${ }^{1}$. La infección por VHZ es habitualmente de fácil manejo pero, en pacientes gravemente inmunosuprimidos (linfocitos T-CD4 $<100$ céls $/ \mathrm{mL}$ ), se puede asociar a diseminación al SNC con vasculitis, leucoencefalitis multifocal, ventriculitis, mielitis y mielo-radiculitis, neuritis

\begin{tabular}{|c|c|c|}
\hline Situación clínica & Terapia de elección & Alternativa \\
\hline Lesiones leves & Aciclovir 400 mg c/8 h 5-10 días (oro-labial) o 7 a 14 días (genital) & Valaciclovir $1 \mathrm{~g}$ vo c/ $12 \mathrm{~h}$ por tiempo similar \\
\hline $\begin{array}{l}\text { Lesiones extensas muco-cutáneas o } \\
\text { con historia de recurrencia }\end{array}$ & $\begin{array}{l}\text { Aciclovir } 5 \mathrm{mg} / \mathrm{kg} \text { iv c/8 h inicial; luego que las lesiones regresen, manejo } \\
\text { similar a lesiones leves y se puede dejar mantención con aciclovir } 400 \text { mg vo } \\
\mathrm{c} / 12 \mathrm{~h} \text { por } 14 \text { días. }\end{array}$ & $\begin{array}{l}\text { Alternativa de mantención valaciclovir } 500 \mathrm{mg} \mathrm{c/} 12 \mathrm{~h} \\
\text { vo por } 14 \text { días }\end{array}$ \\
\hline Encefalitis herpética & Aciclovir $10 \mathrm{mg} / \mathrm{kg}$ iv c/8 h por 21 días & \\
\hline
\end{tabular}


óptica, lesiones de pares craneales y lesiones focales del tronco cerebral ${ }^{106}$. La necrosis exterior retiniana progresiva se presenta en este mismo contexto de paciente y debe diferenciarse de la necrosis retiniana aguda por $\mathrm{VHS}^{107-109}$.

La necrosis exterior retiniana progresiva cursa con mínima inflamación del humor acuoso y vítreo, ausencia de vasculitis retinal y múltiples lesiones periféricas pequeñas en las capas superficiales de retina. Estas lesiones confluyen rápidamente, adelgazan la retina, generan necrosis y desprendimiento con pérdida visual ${ }^{108}$. La gran mayoría de las veces el diagnóstico se establece clínicamente; en los casos con compromiso sistémico se debe recurrir a la biopsia con estudio histopatológico y RPC confirmatoria para virus varicela-zoster. Los cultivos virales son una opción pero tardan más y su pertinencia para el manejo es poco práctica ${ }^{109}$.

\section{Tratamiento}

Aciclovir es el antiviral de elección y valaciclovir una buena alternativa ${ }^{1,108}$ (AII) Tabla 24. Ante la sospecha clínica, es muy importante el tratamiento inmediato, en particular en los casos complicados con compromiso visceral y retinitis. En este último escenario, es difícil diferenciar de una retinitis por CMV ante lo cual se debe indicar cobertura contra este otro virus además, hasta tener confirmado el diagnóstico.

\section{Infección por citomegalovirus}

\section{Diagnóstico}

El citomegalovirus (CMV) compromete a pacientes portadores de $\mathrm{VIH}$ intensamente inmunosuprimidos (linfocitos T-CD4 $<100$ céls $/ \mathrm{mL})^{1}$. La retinitis es su más importante manifestación clínica, es unilateral en $2 / 3$ de los pacientes y, de no mediar terapia, afecta ambas retinas en todos los pacientes. La progresión de la enfermedad, una vez diagnosticada, es muy rápida y puede llevar a la pérdida visual total en períodos tan cortos como 10 a 21 días. Las lesiones retinales evaluadas por un oftalmólogo experimentado, junto con un contexto clínico claro, tienen un valor predictor positivo de $95 \%$. Si existen dudas, se debe realizar una RPC para CMV en humor vítreo ${ }^{110}$. El compromiso de cámara anterior no es habitual y la uveitis se puede ver en el contexto de un SRI, como respuesta a proteínas de CMV latente, sin existir una infección activa. $\mathrm{Su}$ tratamiento es corticostercoidal ${ }^{111-113}$. La colitis ocurre en 5 a $10 \%$ de los pacientes, se caracteriza por fiebre, pérdida de peso, dolor abdominal y diarrea. El estudio por colonoscopia demuestra extensas áreas ulceradas necróticas y es la causa más habitual de perforación intestinal en el paciente con infección por VIH. Pueden presentarse también esofagitis en $\sim 5$ a $10 \%$ de los pacientes; las lesiones clásicamente son únicas, extensas, superficiales y del extremo distal del esófago. Hay fiebre, odinofagia y dolor retro-esternal. El diagnóstico requiere de biopsia. La meningo-encefalitis por CMV puede ser rápidamente letal y se caracteriza por un LCR con pleocitosis linfocitoria, glucorraquia levemente baja e incremento de proteínas. La TAC o RM cerebral demuestran refuerzos periventriculares. El cuadro clínico imita a la demencia por $\mathrm{VIH}^{1}$. La poliradiculopatía se caracteriza por un inicio con dolor lumbar y fiebre, evolucionando a la pérdida del control de esfínteres y paraparesia o paraplejia en la mayoría de pacientes; todo esto, en el lapso medio de cuatro semanas. El LCR muestra pleocitosis polimorfonuclear (650 céls/ $\mathrm{mL}$ como promedio) importante hipoglucorraquia e incremento de las proteínas ${ }^{114}$. La neumonitis es inhabitual, se caracteriza por infiltrados intersticiales y requiere de una biopsia pulmonar compatible para su diagnóstico, descartando otros cuadros más frecuentes ${ }^{1}$. El diagnóstico de infección por CMV se establece comúnmente mediante la demostración de antigenemia pp65 en leucocitos periféricos, el punto de corte para pacientes sometidos a trasplantes está definido en $>5$ núcleos comprometidos por cada 200.000 células. Sin embargo, en los pacientes con infección por VIH no se ha establecido un punto de corte claro y se aplican como significativo valores superiores a 20 núcleos que otorgan una sensibilidad de 77\%, especificidad de 97\%, un VPP 91\% y VPN de $92 \%{ }^{115,116}$. La presencia de virus se puede demostrar en sangre y otros fluidos estériles mediante RPC y representa la principal herramienta diagnóstica ${ }^{117}$.

\begin{tabular}{|c|c|c|}
\hline Situación clínica & Tratamiento de elección & Alternativa \\
\hline Varicela leve no complicada & Aciclovir 800 mg cinco veces/día por siete días & Valaciclovir $1.000 \mathrm{mg} \mathrm{c/8} \mathrm{h} \mathrm{vo} \mathrm{por} \mathrm{siete} \mathrm{días}$ \\
\hline $\begin{array}{l}\text { Varicela grave, en mujer embarazada o complicada con } \\
\text { neumonía o encefalitis }\end{array}$ & Aciclovir $10-15$ mg/kg iv c/8h por 10 a 14 días* & \\
\hline Herpes zoster cutáneo leve o monodermatómico & Aciclovir 800 mg cinco veces/día por siete días & Valaciclovir $1.000 \mathrm{mg}$ c/8 h vo por siete días \\
\hline Herpes zoster multidermatómico o con compromiso visceral & Aciclovir $10-15$ mg/kg iv c/8 h por 10 a 14 días* & \\
\hline Retinitis & $\begin{array}{l}\text { Aciclovir } 10 \mathrm{mg} / \mathrm{kg} \mathrm{c} / 8 \mathrm{~h} \text { iv por } 10 \text { a } 14 \text { días, seguido de } \\
\text { valaciclovir } 1.000 \mathrm{mg} \mathrm{c} / 8 \mathrm{~h} \text { por seis semanas }\end{array}$ & \\
\hline
\end{tabular}




\begin{tabular}{|c|c|c|}
\hline Situación clínica & Terapia de elección & Mantención \\
\hline $\begin{array}{l}\text { Retinitis grave (compromiso visual } \\
\text { acelerado) }\end{array}$ & $\begin{array}{l}\text { Ganciclovir intra-vítreo (ideal implante) + ganciclovir } \\
5 \mathrm{mg} / \mathrm{kg} \mathrm{c} / 12 \mathrm{~h} \text { por } 21 \text { días o valganciclovir } 900 \mathrm{mg} \mathrm{c} / 12 \mathrm{~h} \text { vo } \\
\text { por } 21 \text { días }\end{array}$ & $\begin{array}{l}\text { Ganciclovir } 5 \text { mg/kg día O valganciclovir } 900 \text { mg/día vo } \\
5 \text { a } 7 \text { veces a la semana }\end{array}$ \\
\hline $\begin{array}{l}\text { Retinitis leve (lesiones periféricas sin } \\
\text { compromiso visual) }\end{array}$ & Valganciclovir $900 \mathrm{mg} \mathrm{c} / 12 \mathrm{~h}$ vo por 21 días & Idem \\
\hline Colitis y esofagitis & Ganciclovir 5 mg/kg c/12 h iv por 28 días & Ganciclovir 5 mg/día permanente 5 a 7 veces a la semana** \\
\hline Compromiso SNC & $\begin{array}{l}\text { Ganciclovir } 5 \text { mg/kg c/12 h hasta estabilidad clínica, } \\
\text { se puede asociar foscarnet }\end{array}$ & Idem \\
\hline
\end{tabular}

\begin{tabular}{|lll|} 
& Tabla 26. Tratamiento de la infección por VHH-8 \\
\hline Situación clínica & Terapia de elección & Alternativa \\
\hline SK muco-cutáneo diseminado y/o visceral + PEL* & $\begin{array}{l}\text { Quimioterapia }+ \text { TARV } \\
\text { Ganciclovir puede ser utilizado }\end{array}$ & Ganciclovir como terapia co-adyuvante en PEL \\
Enfermedad multicéntrica de Castleman & $\begin{array}{l}\text { Ganciclovir } 5 \mathrm{mg} / \mathrm{kg} \mathrm{c} / 12 \mathrm{ho} \\
\text { Valganciclovir } 900 \mathrm{mg} \mathrm{c} / 12 \mathrm{~h}\end{array}$ & $\begin{array}{l}\text { Rituximab } 375 \mathrm{mg} / \mathrm{m}^{2} \text { superficie corporal/semanal por } \\
4-8 \text { semanas }\end{array}$ \\
\hline *PEL: primary effusion lymphoma. & & \\
\hline
\end{tabular}

\section{Tratamiento}

El antiviral de elección es ganciclovir que, en el caso de retinitis, además de la terapia sistémica endovenosa, debería administrarse directamente al humor vítreo ${ }^{1,109}$. El tratamiento de mantención para el caso de la retinitis debería seguir por al menos tres meses, hasta la resolución de las lesiones, e idealmente asociado a una recuperación inmune mantenida (linfocitos T-CD4 $>200$ céls $/ \mathrm{mL}$ ). Valganciclovir es el éster valínico de ganciclovir y permite una adecuada absorción administrado por vía oral. Aunque su alto costo limita su acceso en Chile, es una alternativa igualmente válida al ganciclovir ${ }^{118}$ (AI) (Tabla 25). Es necesario señalar que las guías norteamericanas no recomiendan la terapia de mantención, salvo casos de recaídas para las otras localizaciones de infecciones por CMV. Se debe aplazar el inicio de TARV cuando existe compromiso de SNC para luego de la etapa de inducción, pero por otro lado hay evidencia de que asociar terapia anti CMV y TARV durante los primeros tres a seis meses disminuye los fenómenos del SRI asociado y probablemente también decrece la mortalidad ${ }^{119}$.

\section{Infecciones por virus herpes tipo 8 y sarcoma de Kaposi}

\section{Diagnóstico}

La infección por virus herpes tipo 8 (VHH-8) es el fenómeno que gatilla, tanto la formación del sarcoma de Kaposi (SK) y el linfoma primario con efusión (PEL: primary effusion lymphoma) así como la enfermedad multicéntrica de Castleman, que es un desorden linfoproliferativo $^{1}$. Debemos recordar que el SK tiene una fase inflamatoria infecciosa y otra sarcomatosa propiamente tumoral. Las ubicaciones en la región inguinal, pies, boca, pulmón y tubo digestivo se asocian a un peor pronóstico ${ }^{120}$.

El diagnóstico se establece mediante la visión de las lesiones que pueden ser planas o solevantadas, con un color rojo tipo vino tinto. El diagnóstico diferencial se lo hace con la bartonelosis cutánea diseminada que presenta lesiones redondeadas, siempre solevantadas, y de color rojo pálido. La biopsia debe ser hecha preferentemente en lesiones de la piel y establece el diagnóstico definitivo. No se debe tomar biopsia de vísceras por el alto riesgo de sangrado.

La enfermedad de Castleman se caracteriza por adenopatías múltiples y fiebre, y puede gatillar una falla multiorgánica. Requiere estudio anátomo-patológico y determinación de $\mathrm{VHH}-8$ mediante $\mathrm{RPC}^{1}$.

\section{Tratamiento}

La TARV es la principal terapia en el SK y debe ser iniciada inmediatamente. Existe polémica respecto del rol de los antivirales en el manejo del SK, parece estar más claro su utilidad en el PEL y en la enfermedad de Castle$\operatorname{man}^{121,122}$ (BII) (Tabla 26). La quimioterapia y la TARV deben ser iniciada rápidamente en los casos de SK mucocutáneo extenso; no obstante, en los casos cutáneos leves se puede intentar exclusivamente con TARV. Bleomicina, 
Podofilina 0,5\%: aplicar a todas las lesiones c/12 h por tres días, seguidos con cuatro días sin terapia y repetir semanalmente hasta completar cuatro ciclos o imiquimod 5\% crema: aplicar en la noche y retirar en la mañana*, realizarlo día por medio (vg lunes, miércoles y viernes) durante una semana por 16 semanas vincristina y doxorubicina han probado efectividad en el manejo del $\mathrm{SK}^{120}$, siendo doxorubicina liposomal la primera línea de tratamiento.

\section{Leucoencefalopatia multifocal progresiva}

\section{Diagnóstico}

Es una afección causada por el poliomavirus JC que se caracteriza por destrucción de la sustancia blanca cerebral. Se manifiesta con déficit neurológico variable y asimétrico destacando, por frecuencia, la presencia de hemianopsia, hemiparesia, hemiparestesia, dismetria y ataxia. Las lesiones en la leucoencefalopatia multifocal progresiva (LMP) se expanden concéntricamente o a través de los tractos de sustancia blanca, en el transcurso de semanas. Nunca es de presentación abrupta, no se acompaña de cefalea ni fiebre y sólo $20 \%$ desarrolla convulsiones (las lesiones se asientan en la sustancia blanca inmediatamente adyacente a la corteza). La TAC cerebral demuestra zonas hipodensas, habitualmente periventriculares, asimétricas, que no siguen el patrón de territorio vascular, sin efecto de masa y que no captan contraste en 85 a $90 \%$ de las veces, salvo que se encuentre en el contexto de un SRI donde, además de captar contraste, puede existir edema perilesional con efecto de masa. La RM cerebral es el examen imagenológico de elección, demostrando lesiones en la sustancia blanca: hiper-intensas (claras) en T2 y FLAIR e hipo-intensas (opacas) en T1. Debe realizarse RPC para virus JC para confirmar el diagnóstico, el que es positivo en 70 a $90 \%$ de los pacientes ${ }^{123}$. Es ideal tener una RPC negativa para VHZ y para virus de Epstein-Barr y, de ese modo, descartar una infección herpética y linfoma primario de SNC. Se puede realizar una biopsia cerebral en casos seleccionados con alta sospecha de LMP acompañada de pruebas moleculares negativas ${ }^{123,124}$.

\section{Tratamiento}

No existe un antiviral específico y eficiente contra el virus JC; se recomienda como tratamiento de estos pacientes optimizar su condición inmunitaria mediante TARV prefiriendo incluir fármacos con buena penetración al SNC. Los anti-retrovirales que mejor atraviesan la barrera hematoencefálica son: zidovudina, abacavir, emtricitabina, nevirapina, efavirenz, lopinavir/ritonavir, fosamprenavir/ritonavir, darunavir/ritonavir, raltegravir y maraviroc. Se debe intentar armar un esquema con estos fármacos para el paciente con $\mathrm{LMP}^{125-127}$.

\section{Infecciones por virus papiloma humano}

\section{Diagnóstico}

La manifestación clínica de la infección por el virus del papiloma humano (VPH) es la formación de verrugas, papilomas y condilomas sobre el área afectada. Pueden tener diversa localización pero particularmente frecuente son en manos, área génito- urinaria y en la zona perianal ${ }^{1}$.

Pueden derivar en extensas lesiones y más de $30 \%$ de los tipos de VPH que infectan el cérvix uterino son considerados oncogénicos; del mismo modo, este agente es la principal causa del cáncer cervico-uterino. También se encuentra relacionado con el cáncer anal, vulvovaginal, de pene y de la cavidad oral ${ }^{1,128}$. Es fundamental un examen regular ginecológico que incluya un test de Papanicolao y la colposcopia con biopsia cervical directa en los casos en que se encuentre alteración previa. La recurrencia de la infección por VPH es elevada pese al tratamiento ${ }^{1}$.

\section{Tratamiento}

Podofilina e imiquimod, ambos en aplicación tópica, (Tabla 27) son los tratamientos más probados (BII) ${ }^{129,130}$; sin embargo, en localizaciones más complejas u extensas es necesario aplicar crioterapia o cauterización. No pocas lesiones tienen un comportamiento tumoral y la resolución quirúrgica precoz es el tratamiento más adecuado.

Agradecimientos: El autor agradece a los siguientes colegas por la revisión del manuscrito: Elizabeth Barthel, Claudia Cortés, Carlos Pérez C., Luis M Noriega R. y Michel Serri. 


\section{Resumen}

Las presentes guías de diagnóstico y tratamiento de infecciones oportunistas (IO) en el paciente adulto con VIH-SIDA representan una primera aproximación para homogenizar el manejo de estas personas en Chile. Estas guías están basadas en la evidencia científica y buscan ser un instrumento práctico y de fácil manejo para el médico clínico al momento de decidir por las pruebas diagnósticas y tratamientos más eficaces disponibles para sus pacientes. Rescata además las publicaciones y presentaciones chilenas respecto de $\mathrm{IO}$ y se propone su actualización periódica de acuerdo a los avances científicos que se vayan sucediendo.

\section{Referencias}

1.- Guidelines for Prevention and Treatment of Oportunistic Infections in HIV Infected Adults and Adolescents. Recommendations from CDC, National Institutes Health, CDC and HIV Medicine Association of Infectious Diseases Society of America. MMWR Morb Mortal Wkly Rep April 10, 2009; 58 (RR4): 1-207.

2.- Zama M K, White D A. Serum lactate dehydrogenase levels and Pneumocystis carinii: diagnostic and prognostic significance. Am Rev Respir Dis 1988; 137: 796-800.

3.- Hoffmann C. Pneumocystis Pneumonia. En Hoffman C, Rockstroh J HIV 2010 Medizin Fokus Verlag, Hamburg 2010: 324-30.

4.- Baughman R P, Dohn M N, Frame P T. The continuing utility of bronchoalveolar lavage to diagnose opportunistic infection in AIDS patients. Am J Med 1994; 97:512-22.

5.- $\quad$ Maskell N A, Waine D J, Lindley A, Pepperell J, Wakefield A, Miller R, et al. Asymptomatic carriage of Pneumocystis jiroveci in subjects undergoing bronchoscopy: a prospective study. Thorax 2003; 58: 594-7.

6.- Ponce C A, Gallo M, Bustamante R, Vargas S L. Pneumocystis colonization is highly prevalent in the autopsied lungs of the general population. Clin Infect Dis 2010; 50: 347-53.

7.- Zolopa A R, Andersen J, Komarow L, Sanne I, Sánchez A, Hogg E, et al. Early antiretroviral therapy reduces AIDS progression/death in individuals with acute opportunistic infections: A multicenter randomized strategy trial. PLoS ONE 20094 (5): e5575. doi:10.1371/journal. pone. 0005575

8.- $\quad$ Hughes W, Leoung G, Kramer F, Bozzette S A, Safrin S, Frame P, et al. Comparasion of atovaquone (566C 80 ) with trimethoprimsulfamethoxazole to treat Pneumocystis carinii pneumonia in patients with AIDS. N Eng J Med 1993; 328: 1521-7.

9.- $\quad$ Safrin S, Finkelstein D M, Feinberg J Frame P, Simpson G, Wu A, et al. Comparasion of three regimens for treatment of mild to moderate Pneumocystis carinii pneumonia in patients with AIDS: a double blind, randomized, trial of oral trimethoprim-sulfamethoxazole, dapsonetrimethoprim and clindamycin-primaquine. Ann Intern Med 1996; 124: 792-802.

10.- Gluckstein D, Ruskin J. Rapid oral desensitization to trimethoprimsulfamethoxazole (TMP-SMZ): Use in prophylaxis for Pneumocystis carinii pneumonia in patients with AIDS who were previously intolerant to TMP-SMZ. Clin Infect Dis 1995; 20: 849-53.

11.- Helweg-Larsen J, Benfield T, Atzori C, Miller R F. Clinical efficacy of first- and second-line treatments for HIV-associated Pneumocystis jiroveci pneumonia: a tri-centre cohort study. J Antimicrob Chemother 2009; 64 (6): 1282-90.

12.- Smego R, Nagar S, Maloba B, Popara M. A meta-analysis of salvage therapy for Pneumocystis carinii pneumonia. Arch Intern Med 2001; 161: 1529-33.

13.- Briel M, Bucher H C, Boscacci R, Furrer H. Adjunctive corticosteroids for Pneumocystis jiroveci pneumonia in patients with HIV infection. Cochrane Database Syst Rev 2006; 19: 3: CD006150 Review.

14.- Boulware D, Bonham S, Meya D, Wiesner D, Park G, Kambugu A. Paucity of initial cerebrospinal fluid inflammation in cryptococcal meningitis is associated with subsequent immune reconstitution inflammatory syndrome. J Infect Dis 2010; 202 (6): 962-70.

15.- Perfect J R, Casadevall A, Cryptococcosis. Infect Dis Clin North Am 2008; 16: 837-74.

16.- Papas P G, Chetchotisakd P, Larsen R A, Manosuthi W, Morris M I, Anekthananon T. A phase II randomized trial of amphotericin $\mathrm{B}$ alone or combined with fluconazole in the treatment of HIV-associated cryptococcal meningitis. Clin Infect Dis 2009; 48: 1775-83.

17.- Graybill J R, Sobel J, Saag M, van Der Horst C, Powderly W, Cloud G. Diagnosis and management of increased intracranial pressure in patients with AIDS and cryptococcal meningitis. Clin Infect Dis 2003; 30: 47-54.

18.- Meya D, Manabe Y, Castelnuovo B, Cook B, Elbireer A, Kambugu A, et al. Costeffectiveness of serum cryptococcal antigen screening to prevent deaths among HIVinfected persons with a CD4+ cell count $<$ or $=100$ cells $/ \mathrm{microL}$ who start HIV therapy in resource-limited settings. Clin Infect Dis 2010; 51 (4): 448-55.

19.- Fichtenbaum C J, Koletar S, Yiannoutsos C Holland F, Pottage J, Cohn S E, et al. Refractory mucosal candidiasis in advanced human immunodeficiency virus infection. Clin Infect Dis 2000; 30: 749-56.

20.- Gautam H, Kaur R, Goyal R, Bhalla P, Dewan R. Oral thrush to candidemia: a morbid outcome. J Int Assoc Physicians AIDS Care 2010; 9 (5): 325-7.

21.- Pappas P G, Kauffman C A, Andes D, Benjamin D K Jr, Calandra T F, Edwards J E Jr. Clinical practice guidelines for the management of candidiasis: 2009 update by the Infectious Diseases Society of America. Clin Infect Dis 2009; 48 (5): 503-35.

22.- Arathoon E G, Gotuzzo E, Noriega L M Berman R S, DiNubile M J, Sable C A, et al. Randomized, doublé-blind, multicenter study of caspofungin versus amphotericin B for treatment of oropharyngeal and esophageal candidiasis. Antimicrob Agents Chemother 2002; 46 (2): 451-7.

23.- Antinori S, Nebuloni M, Magni C, Fasan M, Adorni F, Viola A. Trends in the postmortem diagnosis of opportunistic invasive fungal infections in patients with AIDS: a retrospective study of 1,630 autopsies performed between 1984 and 2002. Am J Clin Pathol 2009; 132 (2): 221-7

24.- Lortholary O, Meyohas M C, Dupont B Cadranel J, Salmon-Ceron D, Peyramond D, et al. Invasive aspergillosis in patients with acquired immunodeficiency syndrome: report of 33 cases. Am J Med 1993; 95: 177-87.

25.- Guazzelli L S, Unis G, Xavier M O, Severo C B, Picon P D, Severo L C Fungus ball in HIV-infected patients. Rev Inst Med Trop Sao Paulo. 2009; 51 (6): 345-8.

26.- Maertens J, Verhaegen J, Lagrou K, Van Elder J, Boogaerts M. Screening for circulation galactomannan as a noninvasive diagnostic tool for invasive aspergillosis in prolonged neutropenic patients and stem cell transplantation recipients: a prospective validation. Blood 2001; 97: 1604-10.

27.- Segal B H, Walsh T J. Current approaches to diagnosis and treatment of invasive aspergillosis. Am J Respir Crit Care Med 2006; 173: 707-17.

28.- De Pauw B, Walsh T J, Donnelly P, Stevens D A, Edwards J E, Calandra T, et al. Revised definitions of invasive fungal disease from European Organization for Research and Treatment of Cancer/Invasive Fungal Infections 
Cooperative Group and the National Institute of Allergy and Infectious Diseases Mycoses Study Group (EORTC/MSG) Consensus Group. Clin Infect Dis 2008; 46: 1813-21.

29.- Yakiwchuk E, Foisy M, Hughes C. Complexity of interactions between voriconazole and antiretroviral agents. Ann Pharmacother 2008; 42: 698-703.

30.- World Health Organization. Global tuberculosis control-surveillance,planning, financing. Geneva, Switzerland: WHO Report 2007.

31.- Balcells M E, Pérez C M, Chanqueo L, Lasso M, Villanueva M, Espinoza M, et al. A comparative study to different methods for the detection of latent tuberculosis in HIV-positive individuals in Chile. Int J Infect Dis 2008; 12 (6): 645-52.

32.- Callisaya J, Catacora V. Validación del método de concentración con hipoclorito de sodio para el diagnóstico de tuberculosis pulmonar. Biofarbo 2008; 16: 54-60.

33.- Menzies D, Pai M, Comstock G. New test for the diagnosis of latent tuberculosis infection: areas of uncertainty and recommendations for research. Ann Intern Med 2007; 146: 340-54.

34.- Dinnes J, Deeks J, Kunst H, Gibson A, Cummins E, Waugh N. A systematic review of rapid diagnostic tests for detection of tuberculosis infection. Health Technology Assessment 2007; 11 (3): 83-93.

35.- Salech F, Valderrama S, Espinoza M, Salas I, Veas E, Barrera F, et al. Evaluación de test diagnóstico. Utilidad de adenosin deaminasa (ADA) en el diagnóstico de peritonitis tuberculosa. Gastr Latinoam 2005; 16 (3): 262-8.

36.- American Thoracic Society. Diagnostic standards and classification of tuberculosis in adults and children. Am J Respir Crit Care Med 2000; 161: 1376-95.

37.- Programa Nacional de Control de la Tuberculosis "Manual de Organización y Normas Técnicas 2005" Subsecretaria de Salud Pública-División de Control y Prevención de Enfermedades Ministerio de Salud Gobierno de Chile. Norma General Técnica $N^{\circ} 82$. Aprobada por resolución exenta $\mathrm{N}^{\circ} 444$ del 4 de agosto 2005.

38.- Al Moamary M S, Black W, Bessuille E, Elwood R K Vedal S. The significance of the persistent presence of acid-fast bacilli in sputum smears in pulmonary tuberculosis. Chest 1999; 116 (3): 726-31.

39.- World Human Organization. Treatment of Tuberculosis: Guidelines- $4^{\text {th }}$ ed. WHO/HTM/ $\mathrm{TB} / 2009.420$.

40.- American Thoracic Society, CDC and Infectious Diseases Society of America. Treatment of tuberculosis. MMWR Morb Mortal Wkly Rep 2003; 52 (Nº RR-11).

41.- Nahid P, González LC, Rudoy I de Jong B C, Unger A, Kawamura L M, et al.
Treatment outcomes of patients with HIV and tuberculosis. Am J Respir Crit Care Med 2007; 175: 1199-206.

42.- Li J, Munsiff S S, Driver C R, Sackoff J. Relapse and acquired rifampin resistance in HIV-infected patients with tuberculosis treated with rifampin-or rifabutin-based regimens in New York City, 1997-2000. Clin Infect Dis 2005; 41: 83-91.

43.- Balcells ME. Tuberculosis en el paciente con infección por virus de inmunodeficiencia humana. Rev Chil Infectol 2009; 26: 126-34.

44.- Cortés C. McGowan C, Wehbe F, Duda S, Shepherd B, Leger P, et al. Association of tuberculosis treatment duration and intermittency with death and tuberculosis recurrence risk in HIV infected persons. $17^{\text {th }}$ Conference on Retroviruses and Opportunistic Infections. San Francisco 2010. Abstract 783.

45.- Fitzgerald D, Hass D W. Mycobacterium tuberculosis en Mandell, Douglas \& Bennett's Principles and Practice of Infectious Diseases Mandell GL, Bennett JE, Dolin R, eds. $7^{\text {th }}$ Ed. 2010; 3129-64.

46.- Török M E, Yen N, Chau T, Mai N, Phu N, Mai P. Randomised controlled trial of immediate versus deferred antiretroviral therapy in HIV-associated tuberculous meningitis. $49^{\text {th }}$ ICAAC, San Francisco, Ca, September 12-15, 2009. Abstract H-1224.

47.- Organización Mundial de la Salud. Guías de Tratamiento TBC Multiresistente: http://www. who.int/tb/publications/cds_tb2003_313/en/ index.hrml (Accedido: 28 de abril de 2008).

48.- Lasso M, Pérez J. Pericarditis por Mycobacterium tuberculosis multiresistente en un paciente con infección por VIH. Reporte de un caso clínico y revisión de la literatura. Rev Chil Infectol 2009; 26: 156-61

49.- Brown-Elliott B, Wallace Jr R. Infections caused by nontuberculous Mycobacteria en Mandell, Douglas \& Bennett's Principles and Practice of Infectious Diseases Mandell GL, Bennett JE, Dolin R., eds. 6 Ed. 2005; 2768-85

50.- Sande M, Eliopoulos G, Moellering Jr R, Gilbert D. The Sanford Guide to HIV/AIDS Therapy 2008. 16th edition 2008.

51.- Griffith D, Aksamit T, Brown-Elliot B, Catanzaro A, Daley C, Gordón F. An Oficial ATS/IDSA Statement: Diagnosis, treatment and prevention of nontuberculous mycobacterial diseases. Am J Respir Crit Care Med 2007, 175: 367-416.

52.- Phillips P, Bonner S, Gataric N, Bai T, Wilcox P, Hogg R, Nontuberculous mycobacterial immune reconstitution syndrome in HIVinfected patients: spectrum of disease and longterm follow-up. Clin Infect Dis 2005; 41 (10): 1483-9.

53.- Lawn S, Bekker L, Miller R. Immune reconstitution disease associated with mycobacterial infections in HIV-infected individuals receiving antiretrovirals. Lancet Infec Dis 2005; 5 (6): 361-73.

54.- Johnson M, Waller EA, Leventhal JP. Nontuberculous mycobacterial pulmonary disease. Curr Opin Pulm Med 2008, 14: $203-$ 10.

55.- Benson CA, William P, Currier J, Holland F, Mahon L, MacGregor R, et al. A prospective, randomized trial examining the efficacy and safety of clarithromycin in combination with ethambutol, rifabutin or both for the treatment of disseminated Mycobacterium avium complex disease in person with acquired immunodeficiency syndrome. Clin Infect Dis 2003; 37: 1234-43.

56.- May T, Brel F, Beuscar C Vincent V, Perronne C, Doco-Lecompte T, et al. Comparasion of combination therapy regimens for treatment of human immunodeficiency virus-infected patients with disseminated bacteremia due to Mycobacterium avium. Clin Infect Dis 1997; 25: 621-9.

57.- Aberg J, Yajko D, Jacobson M. Erradication of AIDS-related disseminated Mycobacterium avium complex infection after 12 months of antimicobacterial therapy combined with highly active antiretroviral therapy. J Infect Dis 1998; 178: 1446-9.

58.- Dunne M, Fessel J, Kumar P, Dickenson G, Keiser $\mathrm{P}$, Boulos $\mathrm{M}$, et al. A randomized, double-blind trial comparing azithromycin and clarithromycin in the treatment of disseminated Mycobacterium avium infection in patients with human immunodeficiency virus. Clin Infect Dis 2000; 31: 1245-52.

59.- Leal Arranz M V, Gaafar A, Unzaga Barañano Crespo Notario M, Cisterna Cáncer R, García Cebrián F. Clinical and epidemiological study of disease caused by Mycobacterium kansasii in the Metropolitan Area of Bilbao, Spain Archivos Bronconeumol 2005; 41 (4): 189-96.

60.- Serraino D, Puro V, Boumis E, Angeletti C, Girardi E, Petrosillo N, et al. Epidemiological aspects of major opportunistic infections of the respiratory tract in persons with AIDS: Europe, 1993-2000. AIDS 2003; 17: 2109-16.

61.- Redd S C, Rutherford G W, Sade M A. The role of human immunodeficiency virus infection in pneumococcal bacteremia in San Francisco residents. J Infect Dis 1990; 162: 1012-7.

62.- Pintado V, Blazquez R, Loza E, Cobo J, Martin-Dávila P, Fortun J, et al. Streptococcus pneumoniae bacteremia (SPB) in HIV-infected patients: Clinical and epidemiologic changes in the era of the highly active antiretroviral therapy (HAART) $48^{\text {th }}$ ICAAC Vancouver, Canadá. October 25-28, 2008 h-2326.

63.- Rimland D, Navin T R, Lennox J L Jernigan J A, Kaplan J, Erdman J, et al. Prospective study of etiology agents of community-acquired pneumonia in patients with HIV infection. AIDS 2002; 16: 85-95. 
64.- Pérez C, García P, Beroíza T, Calvo M, Bustos M, Vial P, et al. Etiology of pneumonia in Chilean HIV-infected patients. $40^{\text {th }}$ Annual Meeting of the Infectious Diseases Society of America, Chicago, USA. October 2002.

65.- Attridge R, Frei C. Comparison of pneumonia etiology among HIV and non-HIV patients admitted to United States hospitals $49^{\text {th }}$ ICAAC San Francisco, september 12-15, 2009. H-1562.

66.- Lim W S, Baudouin S V, George R C, Hill A T, Jamieson C, Le Jeune I, et al. BTS guidelines for the management of community acquired pneumonia in adults: update 2009. Thorax 2009; 64 Suppl 3: iii1-55.

67.- Sánchez T H, Brooks J T, Sullivan P S, Juhasz M, Mintz E, Dworkin M S, et al. Bacterial diarrhea in persons with HIV infection, United States, 1992-2002. Clin Infect Dis 2005; 45: 1621-7.

68.- Vandana K E, Bairy I, Rao P S, Kabir B. Prolonged fever in HIV disease due to Salmonella enteriditis. Indian J Med Microbiol 2008; 26 (4): 399-400.

69.- Vaughn S, Pearce D D. A case report of recurrent Salmonella meningitis in adult AIDS patient in United States J Int Assoc Physicians AIDS Care (Chic Ill) 2008; 7 (5): 220-2.

70.- Guerrant RL, Van Gilder T, Steiner T S Thielman N M, Slutsker L, Tauxe R V, et al. Practice guidelines for management of infectious diarrhea. Clin Infect Dis 2001; 32: 331-51.

71.- Tramont E C. Treponema pallidum (Syphilis) en Mandell, Douglas \& Bennett's Principles and Practice of Infectious Diseases Mandell GL, Bennett JE, Dolin R., eds.s $7^{\text {th }}$ Ed. 2010; 3035-53.

72.- Centers for Disease Control and Prevention Sexually transmitted diseases treatment guidelines 2002. MMWR Morb Mortal Wkly Rep 2002; 51: 18-30.

73.- Lasso M, Balcell M E, Fernández A, Gaete P, Serri M, Pérez J. Neurosífilis en pacientes portadores y no portadores de VIH: Descripción y comparación de dos cortes históricas. Rev Chil Infectol 2009; 26: 532-9.

74.- Workowski K A, Berman S M. Sexually transmitted diseases treatment guidelines, 2006. MMWR Morb Mortal Wkly Rep RR 2006; RR 55: 1-94.

75.- Marra C M, Boutin P, McArthur J C, Hurwitz S, Simpson P A, Haslett J A, et al. A pilot study evaluating ceftriaxone and penicillin $\mathrm{G}$ as treatment agents for neurosyphilis in human immunodeficiency virus-infected individuals. Clin Infect Dis 2000; 30: 540-4.

76.- Marra C M, Maxwell C L, Tantalo L C, Sahi SK, Lukehart S A. Normalization of serum rapid plasma reagin titer predicts normalization of cerebrospinal fluid and clinical abnormalities after treatment of neurosyphilis. Clin Infect Dis 2008; 47 (7): 893-9.
77.- Zetola N, Klausner J. Syphilis and HIV infection: An update. Clin Infect Dis 2007; 44 (9): 1222-8.

78.- Vázquez P, Chanqueo L, García P, Poggi H, Ferres M, Bustos M. Angiomatosis bacilar por Bartonella quintana en un paciente con infección por virus de inmunodeficiencia humana. Rev Chil Infectol 2007; 24: 155-9.

79.- Sandrasegaran K, Hawes D, Matthew G. Hepatic peliosis (bacillary angiomatosis) in AIDS: CT findings. Abdom Imaging 2005; 30 : 738-40.

80.- Rolain J, Brouqui P, Koehler J. Recommendations for treatment of human infections caused by Bartonella species Antimicrob Agents Chemother 2004; 48: 192133.

81.- Hoffmann C. Cerebral toxoplasmosis. En Hoffmann C, Rockstroh J HIV 2010 Medizin Fokus Verlag, Hamburg 2010: 331-5.

82.- Miranda G, Díaz C, Dellien H, Hermosilla H. Enfrentamiento imaginológico de las lesiones cerebrales en el paciente VIH. Rev Chil Radiol 2008; 14: 200-7.

83.- Kuker W, Nagele T, Korfel A, Heckl S, Thiel E, Bamberg M, et al. Primary central nervous system lymphomas (PCNSL): MRI features at presentation in 100 patients. J Neurooncol 2005; 72: 169-77.

84.- Novati R, Castagna A, Morsica G. Polymerase chain reaction for Toxoplasma gondii DNA in the cerebrospinal fluid of AIDS patients with focal brain lesions. AIDS 1994; 8 (12): 1691-4.

85.- Cinque P, Scarpellini P, Vago L. Diagnosis of cerebral nervous system complications in HIV infected patients: cerebrospinal fluid analysis by the polymerase chain reaction. AIDS 1997; 11 (1): 1-17.

86.- Antinori A, Ammassari A, De Luca A, Cingolani A, Murri R; Scoppettuolo G. Diagnosis of AIDS-related focal brain lesions: a decision-making analysis based on clinical and neuroradiologic characteristics combined with polymerase chain reaction assay in CSF. Neurology 1997; 48 (3): 687-94.

87.- Antinori A, De Rossi G, Ammassari A Cingolani A, Murri R, Di Giuda D, et al. Value of combined approch with thalium-201 single-photon emission computed tomography and Epstein-Barr virus DNA polymerase chain reaction in CSF for the diagnosis of AIDS related primary CNS lymphoma. J Clin Oncol 1999; 17 (2): 554-60.

88.- Leport C, Raffi F, Matheron S Katlama C, Regnier B, Saimot A D. Treatment of central nervous system toxoplasmosis with pyrimethamine/sulfadiazine combination in 35 patients with the acquired immunodeficiency syndrome. Efficacy of long term continuous therapy. Am J Med 1988; 84 (1): 94-100.

89.- Katlama C, De Wit S, O’Doherty, Van Glabeke $\mathrm{M}$, Clumeck N. Pyrimethamine-clindamycin vs pyrimethamine sulfadiazine as acute and long term therapy for toxoplasmic encephalitis in patients with AIDS. Clin Infect Dis 1996; 22 (2): 268-75.

90.- Dannemann B, McCutchan J A, Israelski D Antoniskis D, Leport C, Luft B. Treatment of toxoplasmic encephalitis in patient with AIDS. A randomized trial comparing pyrimethamine plus clindamycin to pyrimethamine plus sulfadiazine. The California Collaborative Treatment Group. Ann Intern Med 1992; 116 (1): $33-43$.

91.- Torre D, Casari S, Speranza F, Donisi A, Gregis G, Poggio A, et al. Randomized trial of trimethoprim-sulfamethoxazole versus pyrimethamine-sulfadiazine for therapy of toxoplasmic encephalitis in patient with AIDS. Italian Collaborative Study Group. Antimicrob Agents Chemother 1998; 42,(6): 1346-9.

92.- Béraud G, Pierre-Francois S, Foltzer A, Abel S, Liautaud B, Smadja D. Cotrimoxazole for treatment of cerebral toxoplasmosis: an observational cohort study during 1994-2006. Am J Trop Med Hyg 2009; 80: 583-7.

93.- Leport C, Meulemans A, Robine D, Dameron G, Vildé J L. Levels of pyrimethamine in serum and penetration into brain tissue in humans. AIDS 1992; 6 (9): 1040-1.

94.- Weitz J, Botehlo R, Bryan R. Microsporidiosis en pacientes con diarrea cronica y VIH/SIDA asintomáticos y pacientes con diarrea aguda. Rev Med Chile 1995; 123: 849-56.

95.- Sartori A M, Ibrahim K Y, Nunes Westphalen E V, Braz L M, Oliveira O C Jr, Gakiya E, et al. Manifestations of Chagas disease (American trypanosomiasis) in patients with HIV/AIDS. Ann Trop Med Parasitol 2007; 101 (1): 31-50.

96.- Apt B W, Heitmann G I, Jercic L M I, Jofré M L, Muñoz C del V P, Noemí H I, et al. Guías clínicas de la enfermedad de Chagas: Parte IV. Enfermedad de Chagas en pacientes inmunocomprometidos. Rev Chil Infectol 2008; 25 (4): 289-92.

97.- López O. Meningoencefalitis chagásica en un paciente con infección por VIH/SIDA con sobrevida a tres años. Caso clínico. Rev Chil Infectol 2010; 27: 160-4.

98.- Bern C, Montgomery S P, Herwaldt B L, Rassi A, Marín-Neto J A, Dantas R O, et al. Evaluation and treatment of Chagas disease in the United States: a systematic review. JAMA 2007; 298 (18): 2171-81.

99.- Apt B W, Heitmann G I, Jercic L M I, Jofré M L, Muñoz C del V P, Noemí H I, et al. Guías clínicas de la enfermedad de Chagas 2006: Parte VI. Tratamiento antiparasitario de la enfermedad de Chagas. Rev Chil Infectol 2008; 25 (5): 384-9.

100.- Li J Z, Sax P E. HSV-1 encephalitis complicated by cerebral hemorrage in HIVpositive person AIDS Read 2009; 19 (4): 153-5. 100a.-Osih R B, Brazie M, Kanno M. Multifocal 
herpes simplex type 2 encephalitis in patient with AIDS. AIDS Read 2007; 17 (2): 67-70.

101.- Fica A, Pérez C, Reyes P, Gallardo S, Calvo X, Salinas A. Encefalitis herpética: Serie clínica de 15 casos confirmados por reacción de polimerasa en cadena. Rev Chil Infectol 2005; 22: 38-46.

102.- Safrin S, Elbeik T, Phan L Robinson D, Rush J, Elbaggari A, et al. Correlation between response to acyclovir and foscarnet therapy and in vitro susceptibility result for isolates of herpes simplex virus from human immunodeficiency virus-infected patients. Antimicrob Agents Chemother 1994; 38: 1246-50.

103.- Meyers J D, Wade J C, Mitchell C D. Multicenter collaborative trial of intravenous acyclovir for treatment of mucocutaneous herpes simplex virus infection in the immunocompromised host. Am J Med 1982; 73: 229-35

104.- Bernstein D I, Spruance S L, Arora S S, Schroeder J L, Meng T C. Evaluation of imiquimod 5\% cream to modify the natural history of herpes labialis. A pilot study. Clin Infect Dis 2005; 41 (6): 808-14.

105.- De Jesus E, Wald A, Schacker T W, Trottier S, Shahmanesh M, Hill J L, et al. Valacyclovir for the suppression of recurrent genital herpes in human immunodeficiency virus-infected subjects. J Infect Dis 2003; 188: 1009-16.

106.- Gebo K A, Kalyani R, Moore R D, Polydefkis $\mathrm{M} \mathrm{J}$. The incidence of, risk factors for, and sequelae of herpes zoster among HIV patients in the highly active antiretroviral therapy era. J Acquir Immune Defic Syndr 2005; 40: 169-74.

107.- Ormerod L D, Larkin J A, Margo C A, Pavan P R, Menosky M M, Haight D O, et al. Rapidly progressive herpetic retinal necrosis: a blinding disease characteristic of advanced AIDS. Clin Infect Dis 1998; 26: 34-45.

108.- Austin R B. Progressive outer retinal necrosis syndrome: a comprehensive review of its clinical presentation, relationship to immune system status and management. Clin Eye Vis Care 2007; 12: 119-29

109.- Holland G N. AIDS and ophthalmology: the first quarter century. Am J Ophthalmol 2008; 145 (3): 397-408.

110.- Arribas J R, Clifford D B, Fichtenbaum C J Commins D L, Powderly W G, Storch G A. Level of cytomegalovirus (CMV) DNA in cerebrospinal fluid of subjects with AIDS and
CMV infection of the central nervous system. J Infect Dis 1995; 172: 527-31.

111.- See R F, Rao N A. Cytomegalovirus retinitis in the era of combined highly active antiretroviral theraphy. Ophthalmol Clin North Am 2002; 15 (4): 529-36.

112.- Walmsley S L, Raboud J, Angel J B, Mazzulli T, Shen S, Casciaro L, et al. Long-term follow up of a cohort of HIV infected patients who discontinued maintenance therapy for cytomegalovirus retinitis. HIV Clin Trials 2006; 7 (1): 1-9. PMID: 16632459.

113.- Jevtovic D J, Salemovic D, Ranin J, Pesic I, Zerjav S, Djurkovic-Djacovic O. The prevalence and risk of immune restoration disease in HIV infected patients treated with highly active antiretroviral therapy. HIV Med 2005; 6 (2): 140-3.

114.- Lasso M, Pérez J, Noriega L M, Albert F, González P, Malebrán A. Polirradiculopatía por citomegalovirus en dos pacientes con SIDA: tratamiento exitoso con terapia antiretroviral de alto grado de actividad (TAAGA) Rev Med Chile 2001; 129: 1061-4.

115.- Salzberger B, Franzen C, Fatkenheuer G, Cornely O, Schwenk A, Rasokat H, et al. $\mathrm{CMV}$ antigenemia in peripheral blood for the diagnosis of CMV disease in HIV infected patients. J Acquir Immune Defic Synd Hum Retrovirol 1996; 11 (4): 365-9.

116.- Wattanamano P J, Clayton J, Kopicko J, Kissinger P, Elliot S, Jarrott C, et al. Comparison of three assays for cytomegalovirus detection in AIDS patients at risk for retinitis. Clin Microbiol 2000; 38 (2): 727-32.

117.- Bowen E F, Wilson P, Cope A. Cytomegalovirus retinitis in AIDS patients: influence of cytomegalovirus viral load on response to ganciclovir, time to recurrence and survival. AIDS 1996; 10: 1515-20.

118.- Martin D, Sierra-Madero J, Walmsley S, Wolitz R, Macey K, Georgiou P, et al. A controlled trial of valganciclovir as induction therapy for cytomegalovirus retinitis. N Engl J Med 2002; 346: 1119-26.

119.- Kempen J, Jabs D, Wilson L, Dunn J, West S, Tonascia J. Mortality risk for patients with cytomegalovirus retinitis and acquired immune deficiency syndrome. Clin Infect Dis 2003; 37: 1365-73.

120.- Lasso M, Pérez J, Noriega L M, Malebrán A, Espinoza S. Sarcoma de Kaposi y VIH: Tratamiento antirretroviral y quimioterapia en 32 pacientes. Rev Med Chile 2003; 131: 483-90.

121.- Cannon J S, Hamzeh F, Moore S, Nicholas J, Ambinder R F. Human herpesvirus 8-encoded thymidine kinase and phosphotransferase homologues confer sensitivity to ganciclovir. Virol 1999; 73: 4786-93.

122.- Neyts J, De Clercq E. Antiviral drug susceptibility of human herpesvirus 8 . Antimicrob Agents Chemother 1997; 41: 2754-6.

123.- Koralnik I J, Boden D, Mai V, Lord C, Letvin N. JC virus DNA load in patients with and without progressive multifocal leukoencephalopathy. Neurology 1999. 52 (2): 253-60.

124.- Tassie J M, Gasnault J, Bentata M, Deloumeaux J, Boue F, Billaud E, et al. Survival improvement of AIDS-related progressive multifocal leukoencephalopathy in the era of protease inhibitors. Clinical Epidemiology Group. French Hospital Database on HIV. AIDS 1999; 13: 1881-7.

125.- Letendre S, Marquie-Beck J, Capparelli E, Best B, Clifford D, Collier A C. Validation of the CNS penetration-effectiveness rank for quantifying antiretroviral penetration into the central nervous system. Arch Neurol 2008; 65 (1): 65-70.

126.- Gasnault J, Hendel-Chavez H, Darasteanu I. Recovery of anti-JCV specific T cell responses and better survival on intensified ART in HIV-1 infected patients with progressive multifocal leucoencephalopathy: The ANRS 125 Trial. IAS Conference Sydney Australia 2007 http:// www.ias2007.org/abstract.

127.- Letendre S. FitzSimons C, Ellis R, Clifford R, Collier A, Gelman B. Correlates of CSF viral loads in 1221 volunteers of the CHARTER Cohort. $17^{\text {th }}$ Conference of Retroviral and Oportunistic Infections 2010. Abstract 172.

128.- Cogliano V, Baab R, Straif K Grosse Y, Secretan B, El Ghissassi F. Carcinogenicity of human papilomaviruses. Lancet Oncol 2005; 6: 204.

129.- Bonnez W, Elswick R K Jr, Bailey-Farchione A. Efficacy and safety of $0,5 \%$ podofilox solution in treatment and suppression of anogenital warts. Am J Med 1994; 96: 420-5.

130.- Gilson R J, Shupack J L, Friedman-Kien A E. A randomized, controlled, safety study using imiquimod for the topical treatment of anogenital warts in HIV-infected patients. AIDS 1999; 13: 2397-404. 